\title{
Idaho National Laboratory Integrated Safety Management FY 2012 Effectiveness Review and Declaration Report
}

December 2012

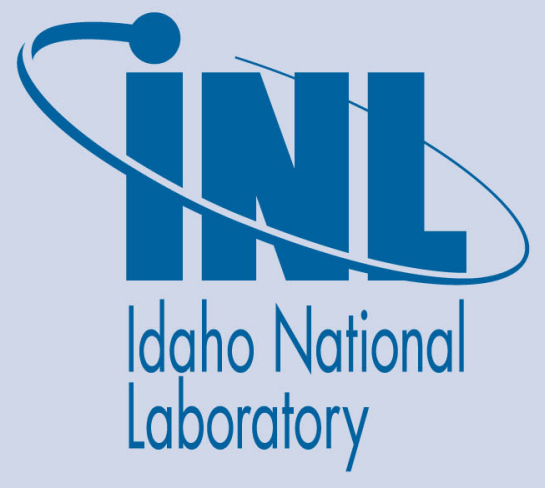

The INL is a U.S. Department of Energy National Laboratory operated by Battelle Energy Alliance 
INL/EXT-12-27860

IAS 13158

\section{Idaho National Laboratory Integrated Safety Management System FY 2012 Effectiveness Review and Declaration Report}

December 2012

Idaho National Laboratory
Idaho Falls, Idaho 83415

http://www.inl.gov

Prepared for the

U.S. Department of Energy

Assistant Secretary for Environment, Safety, and Health

Under DOE Idaho Operations Office

Contract DE-AC07-05ID14517 


\section{DISCLAIMER}

This information was prepared as an account of work sponsored by an agency of the U.S. Government. Neither the U.S. Government nor any agency thereof, nor any of their employees, makes any warranty, expressed or implied, or assumes any legal liability or responsibility for the accuracy, completeness, or usefulness, of any information, apparatus, product, or process disclosed, or represents that its use would not infringe privately owned rights. References herein to any specific commercial product, process, or service by trade name, trade mark, manufacturer, or otherwise, does not necessarily constitute or imply its endorsement, recommendation, or favoring by the U.S. Government or any agency thereof. The views and opinions of authors expressed herein do not necessarily state or reflect those of the U.S. Government or any agency thereof. 
INTENTIONALLY BLANK 


\section{Idaho National Laboratory Integrated Safety Management System FY 2012 Effectiveness Review and Declaration Report}

INL/EXT 12-27860

December 20122

Approved by:

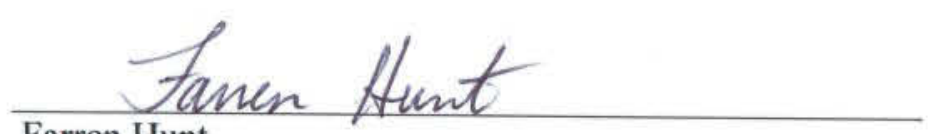

Farren Hunt

Integrated Safety Management Program Manager
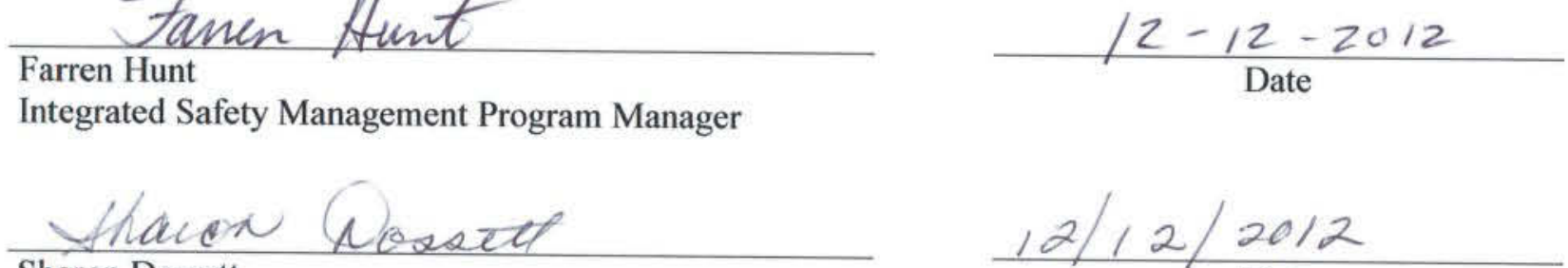

Sharon Dossett

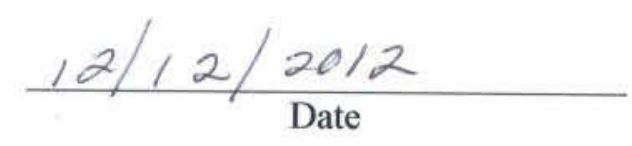

Environmental Safety \& Health Director

$\frac{12 / 13 / 2012}{\text { Date }}$

Carlo Melbihess

Operations Council Chairman 
INTENTIONALLY BLANK 


\section{EXECUTIVE SUMMARY}

Idaho National Laboratory (INL) performed an Annual Effectiveness Review of the Integrated Safety Management System (ISMS), per 48 Code of Federal Regulations (CFR) 970.5223-1, "Integration of Environment, Safety and Health into Work Planning and Execution." The annual review assessed Integrated Safety Management (ISM) effectiveness, provided feedback to maintain system integrity, and identified target areas for focused improvements and assessments for Fiscal Year (FY) 2013.

Results of the FY 2012 annual effectiveness review demonstrated that the INL's ISMS program was significantly strengthened. Actions implemented by the INL demonstrate that the overall Integrated Safety Management System is sound and ensures safe and successful performance of work while protecting workers, the public, and environment. This report also provides several opportunities for improvement that will further strengthen the ISM program and the pursuit of safety excellence. Demonstrated leadership and commitment, continued surveillance, and dedicated resources have been instrumental in maturing a sound ISMS program. Based upon interviews with personnel, reviews of assurance activities, and analysis of ISMS process implementation, this effectiveness review concludes that ISM is institutionalized and is "Effective."

This review analyzed performance data between October 1, 2011 and September 30, 2012, and identified strengths, ongoing initiatives, and opportunities for improvement, which led to the following overall conclusions of the INL ISMS:

ISM processes have been maintained and many have been improved. The ISM processes are comprehensive and have been functioning properly. No elements of the system were identified as having degraded during the year and a number of key actions and initiatives have been implemented to improve the overall structure and success of work control and radiological work performance. Management systems have been maturing in their understanding and oversight responsibilities in implementing ISM core functions and guiding principles from a Laboratory perspective down to the activity level. Improvements and planned improvements in work control and radiological controls addressed weaknesses identified in FY 2011.

The ISMS is effective for performing work safely. The INL ISMS continues to be a well-designed and managed program that encourages continuous improvement and integrates safety systematically into management and work practices to ensure work is accomplished in a manner that protects workers, the public, and environment. A review of work activities that were completed at INL, both successfully and with incident, has demonstrated to the assessment team that when work is completed using the approved tools and processes that are in place at INL, outcomes are accomplished safely and without incident. Interviews have demonstrated that INL has improved the safety culture, increased awareness and attention to detail, improved briefings, increased presence of first line supervision, enhanced work observations, and implemented peer reviews at the Materials Fuels Complex (MFC), the Advanced Test Reactor Complex (ATR), and across the Laboratory.

Improvements in work control. While significant operational events continued as FY 2012 began, INL leadership was incorporating lessons learned from PLN-3762, "INL Work Control Corrective Action Plan," into PLN-4030, "INL Sustained Operational Improvement Plan," to achieve and sustain a high level of operational performance. In addition, three "excellence" plans were developed PLN-4058, "MFC Strategic Excellence Plan," PLN-4141, "ATR Sustained Excellence Plan," and PLN-4145, "Radiological Control Road to Excellence," that detailed the strategies needed to achieve operational performance excellence. Improvements are being realized as these plans and corrective actions were implemented. However, the pace and depth of improvement was not acceptable to management. As a result, PLN-4194, "MFC Response Plan," was implemented in April 2012 in order to assess the weaknesses and failures in the way work was being conducted, evaluate worker competencies, and reinforce performance and 
behavioral expectations. The work stand-down (and subsequent response) was a catalyst to initiate the "step-change" that instilled an understanding of values and expectations (safety, teamwork, ownership, integrity, respect, and continuous improvement) and drove the improvements being realized today.

Continued surveillance and dedicated resources have been a high priority for INL to ensure that successes will continue. Work control and planning make ongoing efforts to ensure the control of activitylevel tasks is adequate and comprehensible and that their efforts control hazards, allowing work to be safely executed. The actions implemented by INL demonstrate that the overall ISMS as a whole is sound and ensures safe and successful performance of work as demonstrated by significant work accomplishments in FY 2012.

ISM Program effectiveness is also substantiated by a number of indicators, performance analyses, data trending, work accomplishments, and assessment results. Occupational injury and illness performance through FY 2012 continues to reflect improvement and is a good indicator of safety culture. FY 2012 has been the safest for Battelle Energy Alliance (BEA) employees since the inception of INL. Twenty-nine recordable occupational injury and illness cases involving BEA employees occurred during FY 2012, resulting in a total recordable case rate (TRCR) of 0.78 . This represents an improvement of $34 \%$ compared to the FY 2004 baseline, and is over 20\% better than FY 2011. Of the 19 major organizations comprising the laboratory, 10 organizations completed FY 2012 without incurring an Occupational Safety and Health Administration (OSHA)-recordable injury or illness. Six of these 10 organizations also had no OSHA-recordable cases during all of FY 2011. In FY 2012, 12 of the 19 major organizations did at least as well or better, from a TRCR perspective, as compared to FY 2011.

The resulting day away, restricted or transferred (DART) Case Rate for FY 2012 is 0.32 . This represents an improvement of over $47 \%$ compared to the FY 2004 baseline, which is almost $40 \%$ better than FY 2011. Of the 19 major organizations in the laboratory, 14 completed FY 2012 without incurring a DART case, and 16 organizations did at least as well or better, from a DART Case Rate perspective, as compared to FY 2011.

FY 2012 has also been the safest for BEA select subcontract employees since the inception of INL. During FY 2012, there were no occupational injuries reported involving employees of select subcontractors that were classified as recordable. The resulting collective Select Subcontractor TRCR for FY 2012 is 0.00 , down from the 2.35 for FY 2011. This metric is not amenable to an annual goal due to the variation in volume of subcontractor work scope and resulting work hours. Rather, the metric is used to monitor individual subcontractor occupational injury and illness performance while performing work onsite, and to take action, as appropriate, if performance does not meet expectations.

Significance Category 2 and 3 (severity) Occurrence Reports submitted by INL for FY 2012 have been trending downward with a total number of reports declining by $15 \%$ as compared to the previous 12-month period.

Significant improvements have been made to INL Training Department and Human Performance Initiatives in FY 2012 that have strengthened the ISMS core functions and guiding principles.

The effectiveness review resulted in no additional new issues, five opportunities for improvement, and seven recommendations.

Conclusion. INL and DOE assessments performed in FY 2012 have confirmed that the actions taken have driven immediate improvement in some cases, and appear to have long-range goals of continual improvement. BEA strongly supports ISMS functions and principles and is committed to continual improvement. The BEA Board and Operations Committee fully support ISMS as evidenced by the corporate resources they provided over FY 2012 to ensure effectiveness of ISMS. All work at INL is managed by processes and procedures that implement the ISMS five core functions and eight guiding 
principles. INL leaders and workers demonstrate a strong, genuine, continual, and personal commitment to ISMS elements at the laboratory, facility, and activity level. Continual improvement, maturation of the contractor assurance system, and continued commitment from the INL leadership have led INL to successfully achieving a breakthrough in reducing safety incidents and improving work planning and control.

\section{Overall Performance Rating - Effective, Continually Improving}


INTENTIONALLY BLANK 


\section{CONTENTS}

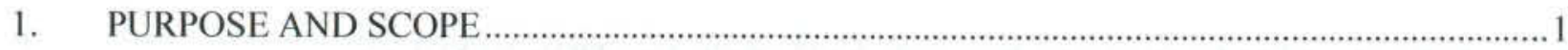

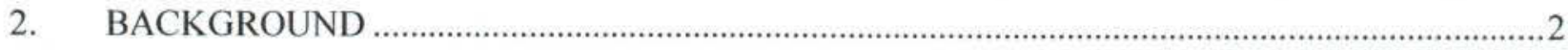

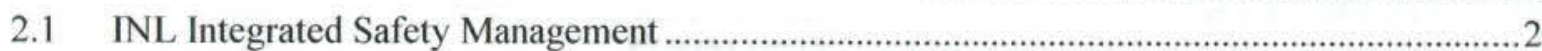

2.1.1 Guiding Principles and Core Functions of ISM at INL ...............................................

2.2 FY 2010 and FY 2011 ISMS Effectiveness Reviews........................................................

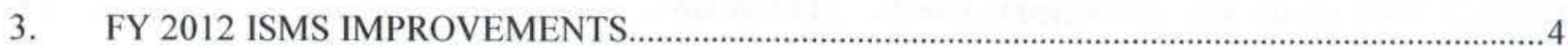

3.1 Work Planning and Control Program Improvements ...........................................................4

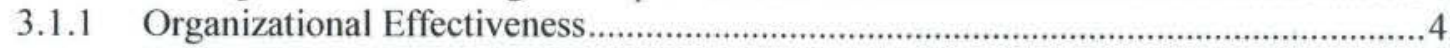

3.1.2 Conduct of Operations and Work Management ......................................................... 5

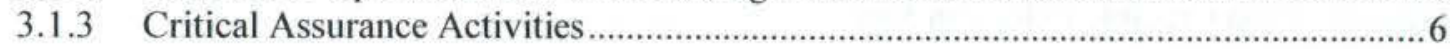

3.2 Radiological Work Control Program Improvements............................................................6

3.2.1 Establish Employee Behavior Consistent Expectations …............................................. 7

3.2.2 Strengthen Radiological Staff through Skill and Knowledge Enhancements ............. 7

3.2.3 Improve Radiological Processes and Procedures ....................................................... 8

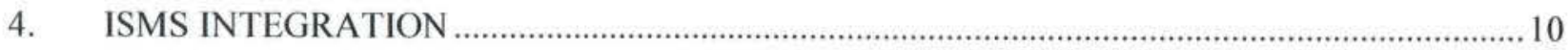

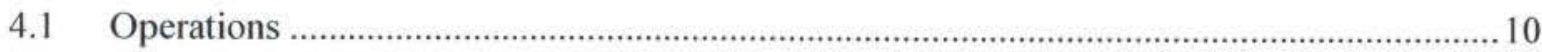

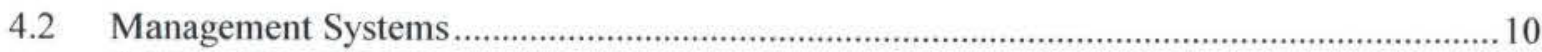

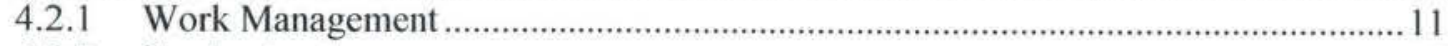

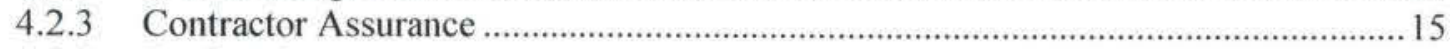

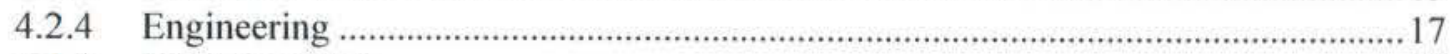

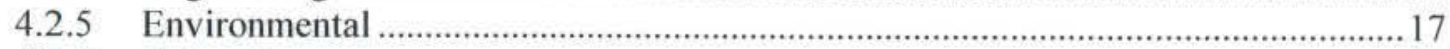

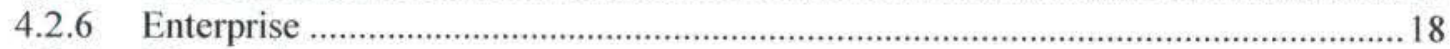

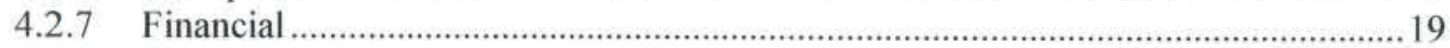

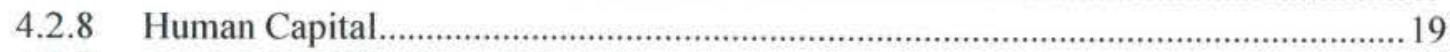

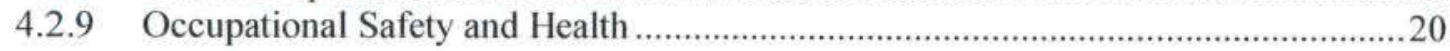

4.3 Leadership Engagement Culture Improvements ....................................................................21

4.3.1 Voluntary Protection Program (VPP) ...................................................................22

4.3.2 Integrated Safety Management System (ISMS) …...................................................22

5. IDENTIFY STRENGTHS OF ISMS IMPLEMENTATION .....................................................24

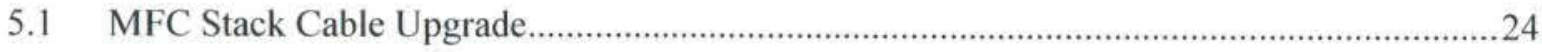

5.2 Cold Crucible Induction Melter (CCIM) ................................................................................25

5.3 Demonstration of Technologies used to Decontaminate Porous Surfaces used for

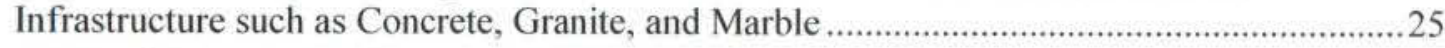

5.4 Hot Fuel Examination Facility (HFEF) Decon Cell Entry and Air Pallet Upgrade ...............26

5.5 Homeland Security E3 EMP Simulation ..................................................................................26

5.6 Radiological Dispersal Device Training …........................................................................26

5.7 GE-2000 Hot Spot Recovery ............................................................................................2

5.8 Zero Power Physics Reactor (ZPPR) Decontamination and Recovery Effort of Fuel Plates 
7. ISMS SAFETY PERFORMANCE OBJECTIVES, PERFORMANCE

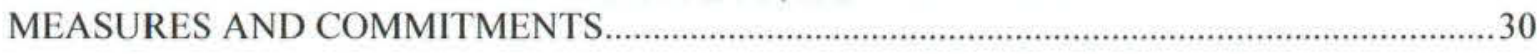

8. ANNUAL EFFECTIVENESS REVIEW AND DECLARATION RESULTS ................................31

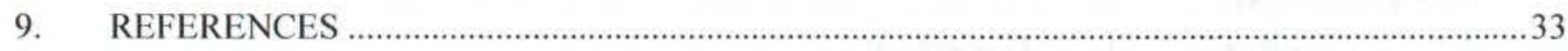

FIGURES

Figure 1. Key sustained operational improvements. ............................................................................. 10

Figure 2. Total occurrences attributed to Conduct of Operations. .......................................................13

Figure 3. Conduct of Operations occurrences involving Lockout and Tagout. .....................................13

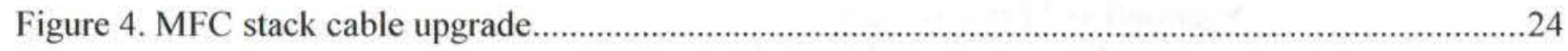

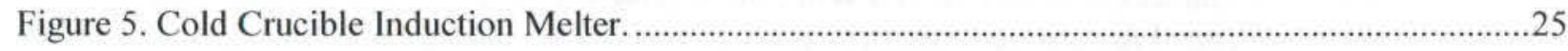

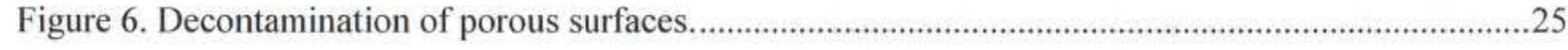

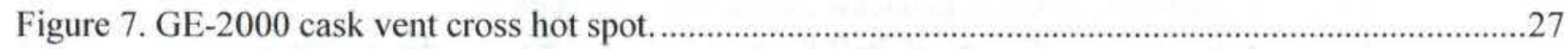




\section{ACRONYMS}

ALARA As Low As Reasonably Achievable

ATR Advanced Test Reactor

BEA Battelle Energy Alliance, LLC

BMP Best Management Practice

CAP Corrective Action Plan

CARB Corrective Action Review Board

CAS Contractor Assurance System

CCIM Cold Crucible Induction Melter

CFA Central Facilities Area

CFR Code of Federal Regulations

CLPIC Critical Lift Person in Charge

CSE Criticality Safety Evaluation

DART Day Away, Restricted or Transferred

DEAR DOE Acquisition Regulation

DOE Department of Energy

DOE-ID Department of Energy Idaho Operations Office

DO-IT Define, Observe, Intervene, and Test

DOORS Dynamic Object-Oriented Requirements System

E\&E Energy and Environment

eCR Electronic Change Request

EDMS Electronic Document Management System

EFCOG Energy Facility Contractors Group

EMS Environmental Management System

EngMS Engineering Management System

EPA Environmental Protection Agency

EPCRA Emergency Planning and Community Right-to-Know Act

EPRI Electric Power Research Institute

ES\&H Environment, Safety, and Health

EST Employee Safety Team

F\&SS Facilities and Site Services

FEC Federal Electronics Challenge

FMS Financial Management System

FY Fiscal Year 


\begin{tabular}{|c|c|}
\hline HaRPS & Hazard and Risk Planning System \\
\hline $\mathrm{HC}$ & Hazard Category \\
\hline HFEF & Hot Fuel Examination Facility \\
\hline HPI & Human Performance Improvement \\
\hline HPT & Health Physics Technician \\
\hline IAS & Independent Assessment System \\
\hline ICAMS & INL Corrective Action Management System \\
\hline INL & Idaho National Laboratory \\
\hline INTEC & Idaho Nuclear Technology and Engineering Center \\
\hline IPA & Integrated Performance Assessment \\
\hline ISM & Integrated Safety Management \\
\hline ISMS & Integrated Safety Management System \\
\hline JON & Judgment of Need \\
\hline LEST & Laboratory Employee Safety Team \\
\hline LMT & Leadership Management Team \\
\hline LO/TO & Lockout/Tagout \\
\hline MFC & Materials and Fuels Complex \\
\hline MHD-E3 & Magneto Hydro Dynamic \\
\hline MRC & Management Review Committee \\
\hline MRM & Management Review Meeting \\
\hline MS & Management Systems \\
\hline MSL & Management System Lead \\
\hline N\&HS & National and Homeland Security \\
\hline OFI & Opportunity for Improvement \\
\hline ONORE & Office of Nuclear Operations and Radiological Control Excellence \\
\hline OSHA & Occupational Safety and Health Act \\
\hline PDD & Program Description Document \\
\hline PEMP & Performance Evaluation Measurement Plan \\
\hline PLN & Plan \\
\hline PPE & Personal Protective Equipment \\
\hline $\mathrm{R} 2 \mathrm{~A} 2 \mathrm{~s}$ & Roles, Responsibilities, Accountabilities, and Authorities \\
\hline RadCon & Radiological Control \\
\hline REC & Research and Education Campus \\
\hline RWP & Radiological Work Permit \\
\hline RTE & Road to Excellence \\
\hline
\end{tabular}


S\&T Science and Technology

SAO System Architect Object

SC Significance Category

SMC Specific Manufacturing Capability

SME Subject-Matter Expert

SPOMC Safety Performance Objectives, Performance Measures and Commitments

TBD Technical Basis Document

TC Training Coordinator

TRAIN Training Records and Information Network

TRCR Total Recordable Case Rate

TREAT Transient Reactor Experiment and Test Facility

VPP Voluntary Protection Program

WCB Willow Creek Building

ZPPR Zero Power Physics Reactor 
INTENTIONALLY BLANK 


\section{Idaho National Laboratory Integrated Safety Management System FY 2012 Effectiveness Review and Declaration Report 1. PURPOSE AND SCOPE}

The purpose of this review is to evaluate the effectiveness of the Integrated Safety Management System (ISMS) at Idaho National Laboratory (INL) for Battelle Energy Alliance, LLC (BEA) for fiscal year (FY) 2012. Integrated Safety Management (ISM) for INL is implemented per Department of Energy (DOE) Integrated Safety Management System Policy (DOE P 450.4A), requirements, and guidance in a manner that applies controls and precautions tailored appropriately to the hazards of the projects and work being performed.

An annual ISMS Effectiveness Review is required by DOE ISMS DOE Acquisition Regulation (DEAR) clause 970.5223-1. This assessment focused on the effectiveness of ISMS implementation in terms of safety performance (including worker safety and health, feedback/improvement, environmental protection, security, emergency management, and quality) and responses to events, assessment results, and lessons learned. The scope of the annual ISM effectiveness review included:

- Determining the effectiveness of integrating safety into work planning, performance, in supporting the safe performance of work, and in improving safety performance

- Identifying strengths and weaknesses of ISMS implementation with focused attention on corrective and improvement actions

- Identifying opportunities for improvement in efficiency or effectiveness of the ISMS, and identifying actions for continuous improvement. 


\section{BACKGROUND}

\subsection{INL Integrated Safety Management}

The composition of INL's ISM program includes several important elements:

- PDD-1004, "Integrated Safety Management System," which describes how the INL implements ISM and incorporates the eight guiding principles of safety and five core functions into work and management at all levels and addresses all types of work and hazards to ensure safety for the workers, public, and environment. PDD-1004 is updated annually and transmitted to the DOE Idaho Field Office (DOE-ID) for review.

- INL Management Systems, which are responsible for defining requirements roll-down and providing oversight responsibilities across the laboratory organizations for successful implementation.

- Collectively, the INL policies, programs, procedures, and culture that fulfill our environmental, safety, health, quality, security, and emergency management responsibilities.

- ISM is inherent to the Laboratory's primary mission: to ensure the nation's energy security with safe, competitive, and sustainable energy systems and unique national and homeland security capabilities.

\subsubsection{Guiding Principles and Core Functions of ISM at INL}

DOE Policy 450.4A, Integrated Safety Management System Policy, contains the following seven guiding principles (INL has adopted an eighth guiding principle of "Employee Involvement") and five core functions that provide guidance and requirements to DOE and its contractors for systematically integrating safety into management and work practices at all levels.

The Eight Guiding Principles must be followed in establishing and performing the five core functions to reach the ultimate safety goal of zero accidents, work-related injuries and illnesses, regulatory violations, and reportable environmental releases.

1. Line management responsibility for safety

2. Clear roles and responsibilities

3. Competence commensurate with responsibilities

4. Balanced priorities

5. Identification of safety standards and requirements

6. Hazard controls tailored to work being performed

7. Operations authorization

8. Employee involvement.

Five Core Functions must be applied, on a graded approach, to all work.

1. Define the scope of work

2. Analyze the hazards

3. Develop and implement hazard controls

4. Perform work within controls

5. Provide feedback and continuous improvement. 


\subsection{FY 2010 and FY 2011 ISMS Effectiveness Reviews}

ISMS annual effectiveness reviews for FY 2010 and FY 2011 both received performance ratings of "Needs Improvement." Relevant points from these reviews include:

- Weaknesses in the areas of work planning and radiological work performance

- The rate of progress toward implementing corrective actions was not acceptable and that INL needed to accelerate both programmatic and operational improvements

- While improvements implemented in work planning and radiological work performance were having the intended effect, more time and perseverance were needed to ensure that the desired outcomes were achieved. 


\section{FY 2012 ISMS IMPROVEMENTS}

\subsection{Work Planning and Control Program Improvements}

BEA management remained committed to improving performance in work control. Several areaspecific and laboratory-wide corrective action plans (CAPs) were commissioned to achieve operational excellence during FY 2012. In addition to focused efforts at MFC, other areas at INL implemented varying degrees of work stand-downs and corrective actions to improve performance in work control. A special oversight group - the Office of Nuclear Operations and Radiological Control Excellence (ONORE) was established to proactively monitor improvement efforts on behalf of the Laboratory Director. The ONORE has noted improvements.

Other assessments and management work observations provided evidence of improvement in the area of work control. Through new planning and work simulation processes, BEA completed several highly complex, high-risk work activities in the last 6 months of FY 2012 without incident. The improvements realized were attributed to a thorough analysis of issues and commitment to the appropriate sustainable actions, behaviors, completion of CAP activities, and strategic improvement plans. Key actions in the INL Sustained Operational Excellence Plan focused on improvements in the following areas. Area-specific plans are focused in large part on the same areas, but addressing unique issues for their organizations.

\subsubsection{Organizational Effectiveness}

1. A leadership survey and oral boards were conducted in organizations performing higher-risk operational activities to determine competency, attitude, and commitment of incumbent first-line supervision and managers. This activity was initiated at MFC but has influenced improvements to other organizations. The results of these boards were used to make immediate adjustments to the leadership team to position BEA for sustainable change in operational performance.

2. Research was performed on first-line managers and above in organizations performing higher-risk operational activities to determine where weaknesses exist among incumbent leaders. Key performance data was reviewed including oral board results, safety leadership survey results, Gallup survey results, injury/illness rates, and incident rates. Actions were taken to coach, mentor, reassign, or terminate line management as appropriate to strengthen the operational leadership team.

3. Management presence in the field has been significantly strengthened. Line management performs routine work observations to communicate expectations related to work planning and execution, ensure that expectations are being met, and to foster a trusting relationship between management and workers such that issues and inefficiencies are addressed in an effective manner. Issues and observations identified through this process are documented in ICAMS for trending purposes.

4. Strong performers identified during the research discussed in (1) above and external experts in Work Control/Conduct of Operations have been utilized in mentoring incumbent first line supervisors and above. Mentoring has been ongoing at MFC, Facility and Site Services (F\&SS), Advanced Test Reactor (ATR), and Specific Manufacturing Capability (SMC) to strengthen management skills, demonstrate "what good looks like," and achieve alignment of expectations.

5. A process was established to more systematically assess, select, promote, and demote INL leadermanagers. A Management Review Board concept has been approved and will be implemented in early FY 2013 for future Level 1 and 2 management decisions.

6. Human performance standards, tools, and expectations have been established for workers, supervisors, and managers. Human performance principles have been incorporated into work control and conduct of operations procedures. 


\subsubsection{Conduct of Operations and Work Management}

1. A Work Management Steering Committee comprised of senior Environment, Safety, and Health (ES\&H) management and senior Operations Management from across the site was formed to (1) ensure standardization of work management processes where appropriate, (2) incorporate specificity and clarity in standards, (3) monitor operational performance across the Laboratory, and (4) support the management system to foster continuous improvement in operations through the use of key performance metrics, mentoring, and other tools. This committee has been instrumental in effecting change in work control and conduct of operations and establishing the appropriate set of assurance activities for FY 2013 to ensure sustainment of improvements.

2. Completed improvements to the Maintenance Work Control process that strengthened roles and responsibilities, clarified expectations for planning walkdowns, improved the integration of radiological controls into work planning, provided improved direction for determining the planning level of work based on risk and complexity, and ensured better engagement of engineering personnel for post-maintenance testing. Although most organizations have implemented the approved changes to this process, the procedure will be effective in early December 2012 when the training is complete. Further improvements to operational performance are expected to be realized as a result of these changes in FY 2013.

3. Dynamic Learning Centers have been established at the Research and Education Campus and the Central Facilities Area. These centers provide hands-on training environments for work planning, lockout/tagout (LO/TO) simulations, management observations, and other conduct of operations principles.

4. Substantial enhancements were made to the Planner Qualification Program to more adequately prepare planners for their responsibilities for hazard identification and control. An Electric Power Research Institute (EPRI)-endorsed, performance-based planner qualification program has been approved that includes dynamic learning exercises using various simulators. All planners will be required to requalify under the new program. In addition, junior planners will be mentored by experienced planners until an adequate level of competence is reached. Training classes will begin in December 2012/January 2013.

5. The INL Hazard and Risk Planning System (HaRPS) computer tool used by planners to identify hazard controls once the hazards are determined during the planning walkdown, is undergoing a modification nearing completion that will provide planners with a more refined selection capability for hazard controls. This modification will narrow the output provided to the planners and resolve the issue of planners having to sort through an overabundance of information to pinpoint the appropriate job-specific hazard controls. Planners, ES\&H personnel, and other technical experts were actively engaged in defining the scope of the modification. The new tool is expected to be in use in the January/February 2013 timeframe.

6. A Planner's Guide was developed in conjunction with the modification to LWP-6200, "Maintenance Integrated Work Control Process," to provide detailed guidance to planners related to the content and format of work control documents. The guide will provide additional consistency in work control document across the site and eliminate error likely situations when workers move from one area to another. The guide will be issued in December 2013. 


\subsubsection{Critical Assurance Activities}

1. The interface between Management System Leads and Line Management is being strengthened to improve INL ability to predict and prevent systemic operational issues and effectively implement improvement actions. The Work Management Steering Committee and the Work Management System Lead have defined a set of assurance activities to be monitored during FY 2013 to determine the effectiveness of FY 2012 corrective actions.

2. An Integrated Performance Assessment (IPA) function was established by the Laboratory Performance organization. IPAs will consist of multi-discipline reviews of approved and implemented management systems within a facility and/or division that are critical to support ISMS and INL mission success. Each IPA emphasizes effective work control practices, management engagement, and worker involvement. Additional focus areas are established by facility/division management based on risks or known problem areas. An IPA of the Specific Manufacturing Facility was completed in the second quarter of FY 2012. A CAP was developed and actions were completed.

3. Improved roles, responsibilities, accountabilities, and authorities (R2A2s) for Management System Lead and Functional Leads now require an annual assessment of training effectiveness evaluating the effectiveness of training to ensure competence commensurate with responsibilities was recognized as a weakness during FY 2012.

An evaluation of work control issues identified in the Issues and Corrective Action Management System (ICAMS) indicates that additional improvements are needed in the quality of work control documents. Improvements to be made in FY 2013 are focused on improving work control document quality. Additional improvements have recently been initiated that will establish methods for addressing routine hazards outside of the work control document, allowing the work control document to focus on job-specific hazards.

\subsection{Radiological Work Control Program Improvements.}

BEA management maintained its commitment to improve Radiological Work Performance. The areaspecific and laboratory-wide action plans implemented to achieve operational excellence during FY 2012 also addressed radiological work performance. In addition to the area specific plans, the Radiological Control organization developed PLN-4145, "Radiological Controls Road to Excellence (RTE)," to address the issues, risks, and challenges associated with radiological control events across the laboratory. BEA's commitment to these improvements was demonstrated by upper management commissioning ONORE, which was tasked with monitoring the progress of the plan, its implementation, and the effectiveness of the plan's activities. In addition, the Operations Council, Executive Council, and Operations Committee actively monitored the progress of the plan through regular reports and briefings. The culmination of the more serious events caused a re-focus of improvement strategies at MFC to prioritize safety culture (behaviors) as a foundational corrective action. While behaviors became a primary focus, other programmatic actions continued.

Several assessments conducted at the end of the FY 2012, concluded that the RTE was a valuable tool and implemented corrective actions were overall "On Track." The corrective actions had achieved their intended effect with sustained actions that were put in place. The assessments also noted a visible improvement in safety behaviors and competencies. Continued nurturing of safety culture and engagement of employees was viewed as critical in maturing to a resilient organization. The assessments also noted that planned FY 2013 improvements in the Radiation Work Permit (RWP), As Low As Reasonably Achievable (ALARA) process, and addressing additional staffing needs will be key to the success of RTE. Interim improvements in all three areas have been put in place and final actions will be completed in FY 2013. Other recommendations included improved integration with other organizations in planning and proposed program changes as well as continued vigilance in ensuring that implemented 
corrective actions are timely and meet the intended outcome. The three major improvement areas in FY 2012 were identified and addressed in the RTE plan as follows:

- Establish employee behavior consistent with expectations

- Strengthen radiological staff through skill and knowledge enhancements

- Improve radiological processes and procedures.

Key actions taken in FY 2012 are in the following subsections.

\subsubsection{Establish Employee Behavior Consistent Expectations}

1. Radiological Control Management presence in the field has been significantly increased. The ES\&H Director established an office at CFA and spends a minimum of 2 days a week at the Site. The Radiological Control Director temporarily relocated to MFC to oversee the work planning and execution to ensure that expectations are met. The Radiological Control Manager at MFC is in the process of hiring a deputy to assist in managing the facility's radiological control program at MFC.

2. Radiological Control Management completed oral evaluations of MFC Radiological Control (RadCon) staff to assess their individual understanding of MFC values and expectations. The staff signed-off on a personal accountability commitment to hold themselves, coworkers, and their supervisors/managers accountable to standards of behavior for safe, sustainable operations. Improvement actions were also taken for those employees who did not pass their oral board.

3. Weekly Engagement Meetings with MFC staff and a RadCon Newsletter were instituted to improve communications and engage staff. The weekly engagement meetings have proven to be a valuable forum to screen intended program changes and promote dialogue between management and staff. This dialogue also has extended outside the RadCon organization. As an example, the Deputy Laboratory Director for Research and Development was asked to lead a discussion of how the RadCon organization supports the mission of the laboratory.

4. Re-enforcement of values and expectations has also been improved through recognition of safe behaviors. Several group awards and recognition meals have been given for exemplary performance and behaviors, as well as "Safe Behavior" lunch cards piloted. The groups recognized included RadCon support for the successful removal of the GE2000 hot spot (4000R/hr) and recovery efforts related to the Zero Power Physics Reactor (ZPPR) event, as examples.

\subsubsection{Strengthen Radiological Staff through Skill and Knowledge Enhancements}

1. An increase in the number of credentialed staff was an initial focus. A credentialed Sr. Radiological Engineer was hired as the subject matter expert (SME) for RadCon as well as a Sr. RadCon Manager to assist in the management of the programmatic functions. A well respected retired former INL RadCon Manager was also hired as a subcontractor to lead revisions to the RadCon Manual and reinstitute best management practices, which had been removed over time.

2. Organizational changes have aligned appropriate skill sets and duties. All manager and supervisor positions were evaluated based on oral board reviews and other criteria and adjustments were made. RadCon assignments are now aligned to the new MFC organizational structure, a MFC Instrumentation Group was created to reduce competing priorities and RadCon leads were created to assist supervisors and allow them more time in the field. These changes will be monitored for effectiveness as the new MFC organization matures. Additional staffing needs are continually being assessed and prioritized with other needs by line management. 
3. Facility Specific Health Physics Technician (HPT) Training has now been developed and given for 10 of the 13 major facilities at MFC. The facility specific training for the remaining facilities is under development and is scheduled for completion by April 2013.

4. An impact analysis for training development and radiological worker qualifications was completed at the MFC. As a result, a Lab Worker II Training is developed for those employees whose primary function is to work in laboratory fume hoods, glove boxes, and bench tops. In addition, an extremity tracking card has been deployed to improve knowledge and skills of Radiological (Rad) Workers. The training techniques and standards have also been revised with much more rigor for Rad Worker II training.

\subsubsection{Improve Radiological Processes and Procedures}

1. Improvements have been made to critical RadCon Performance Assurance activities. These include a revamp of metrics and associated data that focus on high-volume, low-threshold performance measures, a revised assurance portfolio that assesses risk areas with more rigor, and scheduling opportunities for emerging risk areas. Pending data management improvements will improve the efficiency of data collection. Use of ICAMs data is maturing as the new performance measures gain more run time. Continual improvements in this area are expected as new or improved processes are invoked and metrics may be developed, as appropriate, to measure progress. It may be necessary in certain instances to modify or supplement tasks to achieve the results necessary to improve the Radiological Work Performance.

2. The INL PDD-15001, "Air Monitoring Technical Basis Document (TBD)," was developed and issued to address issues with the air monitoring program. In addition, the procedures implementing the TBD were revised, issued, and the appropriate staff trained. In summary, the TBD found the balance of INL, excluding MFC, to be compliant with some recommended improvements to enhance the program. CAPs related to MFC are included in the RTE plan.

3. Revisions and approval of the companywide LRD-15001, "Radiological Controls Manual," to include best management practices (BMPs) and more rigor in the processes is a major undertaking and still in progress. In summary, a majority of the revisions have been completed with RWP and ALARA reviews being the last major revision planned for completion midyear FY 2013. An implementation plan is being developed to manage significant changes and impacts on lower tiered procedures, potential cost impacts, and staff. Changes include:

Update the RWP standards to include the use of general and job specific RWPs based on hazards.

Revise the trigger levels that require formal radiological review of work activities by the ALARA committee.

4. Update and revise the radiological control software system (Sentinel):

a. Revise the RWP module to facilitate the development of general and job-specific, hazard-based RWPs.

Add a module to track the status of employees in the INL Bioassay program. This is necessary to ensure workers are properly monitored and to address several assessment observations and findings.

Add a metrics module to facilitate analysis and trending.

5. Based on lessons learned, an extent of condition assessment was completed on 1,484 accountable and exempt sealed radioactive sources. Health Physics technicians assigned to the project met with the source custodians to physically verify the location of sources, inspect and perform surveys, examine the custodians' records, and evaluate the custodian's knowledge regarding the source program. Improvement opportunities resulting from this assessment are tracked in ICAMS. 
6. Complete revisions to various RadCon procedures necessary to support Radiological Control Manual improvement. High priority procedures related to specific event corrective action plans are being executed. Examples of the types of changes include:

a. Revise the radiological work permit procedures to include the use of general and job-specific, hazard-based RWPs. Train staff to the updated standards.

b. Reduce the number of Personal Protective Equipment (PPE) categories to four from 26 to limit error likely situations.

c. Evaluate INL radiological control posting and labeling standards for consistency. Update postings in the facilities and at outdoor locations.

7. The DOE Accident Investigation Review Board and MFC Judgment of Need (JON) actions assigned to the RadCon Organization are being completed, as scheduled.

INL is committed, with these improvements, to obtain the desired effectiveness. 


\section{ISMS INTEGRATION}

\subsection{Operations}

BEA allocated significant resources in FY 2012 to improve work and safety performance, and establish a comprehensive strategy that was to drive and sustain operational improvements. The desired outcome of this heightened response was to transition from a "reactive" mode and cycle (event-driven), to a proactive mode in which operational performance is closely monitored, evaluated and emerging risks are identified and mitigated before an event is realized.

As FY 2012 began, INL leadership was incorporating lessons learned from PLN-3762, "INL Work Control Corrective Action Plan," into PLN-4030, "INL Sustained Operational Improvement Plan," to achieve and sustain a high level of operational performance. In addition, three "excellence" plans were developed (PLN-4058, "MFC Strategic Excellence Plan," PLN-4141, "ATR Sustained Excellence Plan," and PLN-4145, "Radiological Controls Road to Excellence Plan") that detailed additional strategies needed to achieve operational performance excellence. Even though these plans and corrective actions were being implemented, and improvements were being realized, the pace and depth of improvement was not acceptable to management. As a result, PLN-4194, "MFC Response Plan," was implemented in April 2012 to reinforce performance and behavioral expectations, while also re-evaluating weaknesses and failures in the way work was being conducted and in worker competencies. The work stand-down (and subsequent response) was a catalyst to initiate the "step-change" that instilled an understanding of values and expectations (safety, teamwork, ownership, integrity, respect, and continuous improvement) and drove the behavioral improvements being realized today.

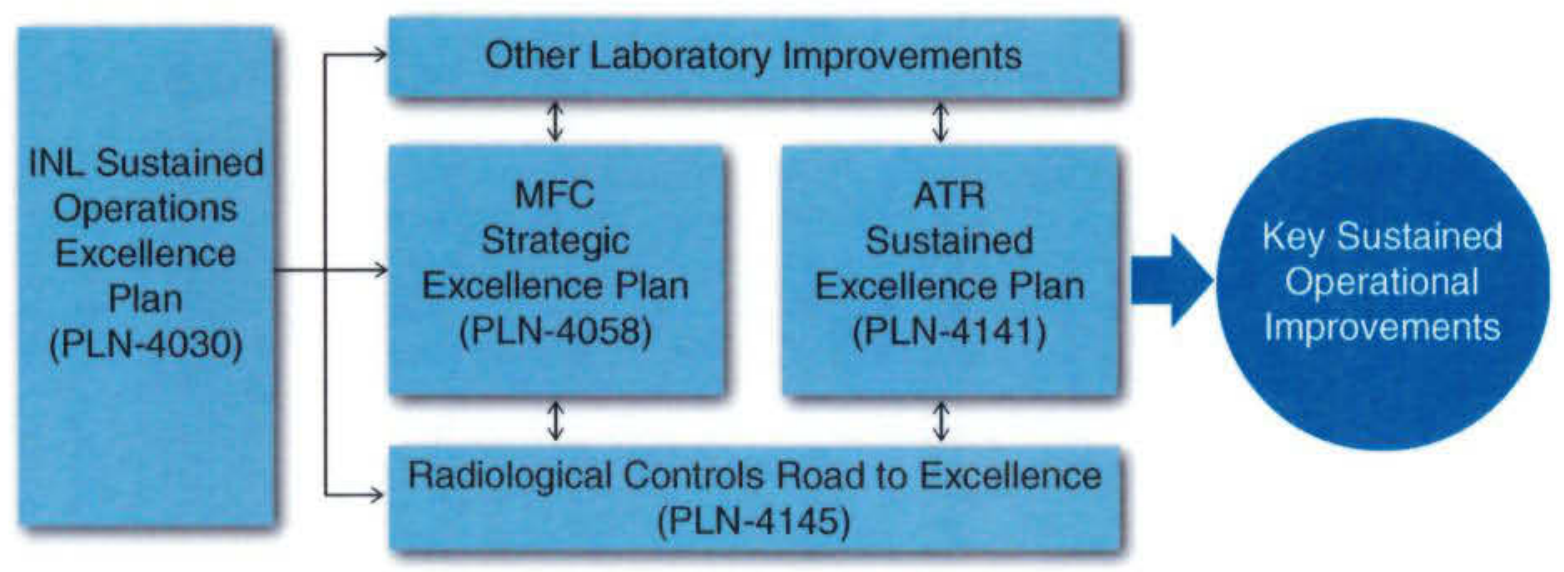

Figure 1. Key sustained operational improvements.

\subsection{Management Systems}

As the functional processes and business systems used to "run" the laboratory, INL management systems translate requirements and best-practices into process controls and tools that enable safe, effective, and compliant performance. In addition to the previously mentioned improvements in work control and radiological work performance in Section 3, notable improvements in the Management Systems were also accomplished. These include:

- Routinely meetings with the Leadership Management Team to help educate them on the purpose of each MS, issues, risks and strategic improvement initiatives

- Routine oversight and reporting of MSs to their respective councils 
- Performance monitoring and evaluation with quarterly reports has improved. Emphasis with respect to timeliness and availability to the Contractor Assurance Portal (CAS) is expected for FY 2013 for all MSs

- Resumption of monthly MS Lead meetings and cross-sharing of information

- Refocused leadership training on MSs in Mandate-to-Manage

- Use of a peer review to assess the Technology Development MS

- Improved presence and accessibility of MSs on the INL Nucleus; including a new web presence for Work Management, and tools for MS leads

- Expectations for the incorporation of ISM into MSs reinforced through revised MS R2A2s, new MS processes, one-on-one and peer group discussions, and goal setting/annual review performance evaluations of those involved with leading and managing INL MSs.

INL MSs are based on the principle of continually improving in key areas that impact the sustainability of the business, encompass sharing, promote process optimization and management focus and disciplined management thinking. The ISMS program manager has been working closely with the Management System Administrator and the Management System Leads (MSLs) throughout FY 2012 to improve ownership, understanding, and effective implementation of key ISMS core functions and guiding principles from a laboratory perspective. Starting in FY 2012, Safety Performance Objectives Metrics and Commitments (SPOMC) were incorporated into and reported via MS Quarterly Assurance Reports and provided for DOE-ID review on the CAS portal.

In addition to improvements in the quality of metrics and critical evaluation of performance as documented in the content of quarterly assurance reports, each of the MSLs was challenged to better understand the application and implementation of ISM in their MS by being more self-critical to improve their efforts to protect people, environment, and assets. Also they were challenged to develop measurement tools to examine and identify ISM deficiencies and incidents to prevent them from recurring in the future.

The addition of a consistent risk framework for planning assurance activities and reporting was implemented in late FY 2012 to the assurance portfolio process (Template-13730).

In FY 2012 each MSL provided summary evaluations of their respective management system's health and performance for FY 2012 to the ISMS program manager. These evaluations included accomplishments, opportunities for additional improvements, and ongoing initiatives. The review of these evaluations demonstrated effective ISM implementation at the INL. The following subsections are a few sample results and excerpts from these evaluations.

\subsubsection{Work Management}

In addition to all of the previously mentioned improvements and initiatives to Work Management (see Section 3), the Work Management MS has taken on several other key functional areas and is in the process of incorporating them and the associated metrics into their assurance portfolio.

Conduct of Operations. Many of the improvements noted above under Work Control are also aimed at improving the execution of Conduct of Operations principles. Specifically, the oral boards and leadership research targeted behaviors and issues that are indicators of strengths/weaknesses in Conduct of Operations. Continual coaching and mentoring of first line supervisors and above with focus on promoting a strong "Conduct of Operations Culture." The Work Management Steering Committee is focused on completing specific Conduct of Operations standards, monitoring performance in Conduct of Operations, and designing and implementing a more robust training program. And the dynamic learning 
centers will be used to perform hands-on LO/TO training as well as other Quarterly Conduct of Operations training.

The briefing process has also been strengthened to emphasize reverse briefing techniques since these techniques are much more powerful in engaging the workers and creating a common understanding of roles and responsibilities for the specific work to be performed. Efforts are also ongoing to incorporate human performance techniques and tools into Conduct of Operations and work control processes.

Conduct of Operations requirements have been effectively rolled down into implementing procedures for many years. During FY 2012, BEA has been evaluating and revising specific procedures with two primary objectives:

- DOE revised the directive for Conduct of Operations (formerly DOE O 5480.19) with the most significant change being its applicability. The new DOE Order 422.1, Conduct of Operations, has limited the applicability to Hazard Category (HC) 1, 2, and 3 nuclear facilities. BEA has committed to implementation of four elements of Conduct of Operations across the Laboratory. (Organization and Administration, Investigation of Abnormal Events, Notifications, and Lockout and Tagout). BEA is evaluating implementation of the remaining 14 elements in other than $\mathrm{HC} 1,2$, and 3 facilities using a measured, strategic, sustainable, and safe approach to maintain practices that promote operational and mission excellence, and eliminate practices that are not value-added.

- The INL Sustained Operational Excellence Plan contains actions to provide greater specificity and clarity in Conduct of Operations standards for each area to ensure that roles, responsibilities, and methods for implementation in each unique situation are clearly delineated. These revisions are nearing completion for nuclear facilities. A set of conduct of research documents is also being developed for research activities to provide clear roles, responsibilities, and methods for those elements of Conduct of Operations that promote excellence in research.

Detailed metrics for Conduct of Operations are under development for FY 2013.

Lockout and Tagout. While the total number of occurrences attributable to Conduct of Operations has decreased in FY 2012 as depicted in Figure 2 below, the number of occurrences involving LO/TO has slightly increased as depicted in Figure 3. Late in FY 2012, BEA recognized an apparent trend in LO/TO events. In October 2012, the BEA Operations Council commissioned a common cause analysis of issues and events involving the implementation of $\mathrm{LO} / \mathrm{TO}$ work control practices to determine if there were similarities. Fourteen issues and events that occurred between April 2012 and October 2012 were analyzed, many of which did not reach the threshold of occurrence reporting. The analysis focused on the individual and institutional behaviors as opposed to the LO/TO process and procedures. The two most common causes identified were: (1) Task Analysis is Less-Than-Adequate, with most problems occurring during preparation of the $\mathrm{LO} / \mathrm{TO}$, specifically with the proper identification of recommended controls; and (2) Personnel did not perform Work Correctly, where work was performed in a manner that did not comply with the approved work authorization and control documents. These errors were most often coupled with less-than-adequate oversight. The final cause analysis report will be issued in late November. A corrective action plan is in the process of being developed to address these issues. 


\section{Conduct of Operations}

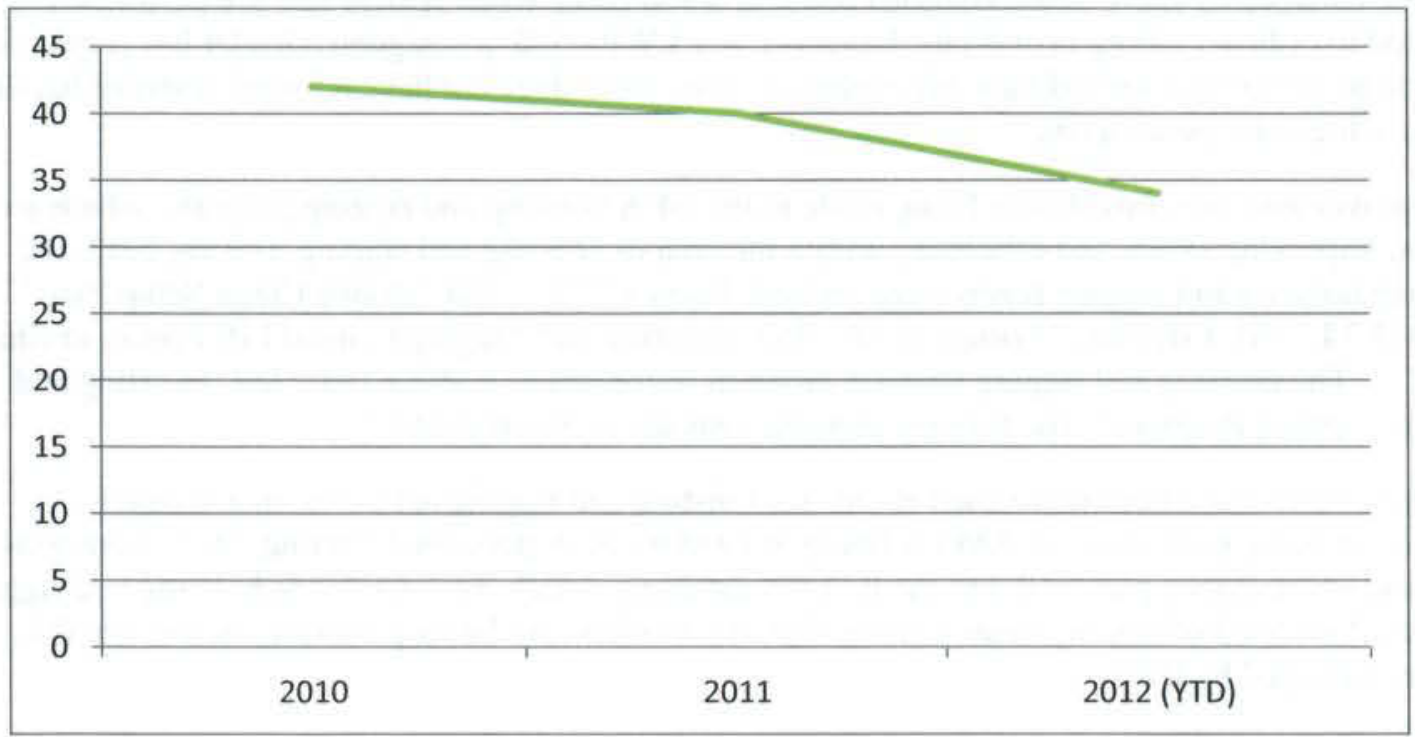

Figure 2. Total occurrences attributed to Conduct of Operations.

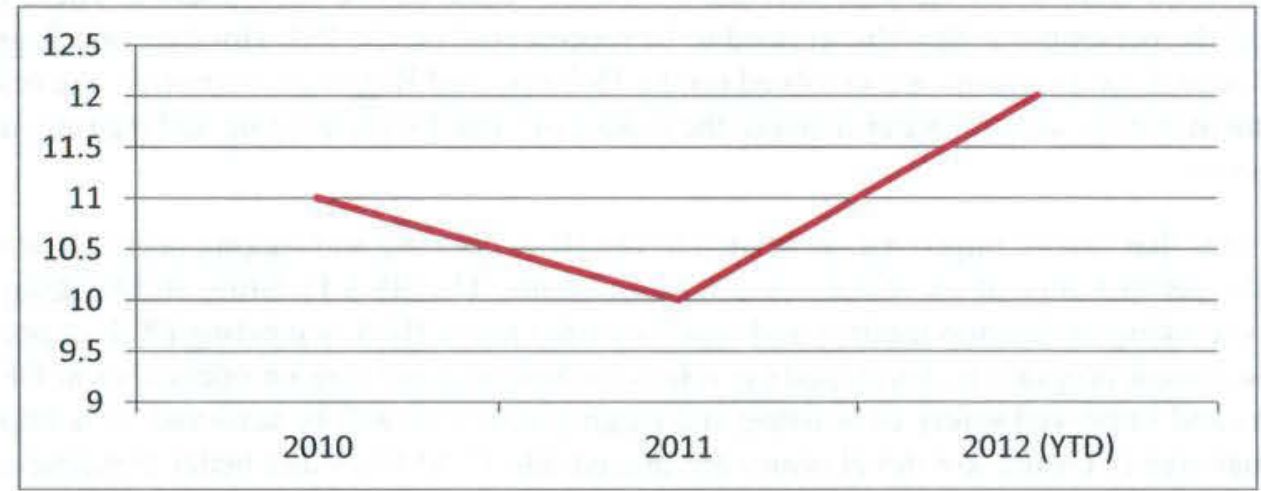

Figure 3. Conduct of Operations occurrences involving Lockout and Tagout.

Hoisting and Rigging. During FY 2012 the BEA Hoisting and Rigging program continued to be strengthened and aligned with DOE requirements and national consensus standards. The BEA Hoisting and Rigging program basis document is DOE-STD-1090-2011, "DOE Standard Hoisting and Rigging." DOE-STD-1090 was revised in the late 2011 timeframe. The 2011 revision of DOE-STD-1090 requires that hoisting and rigging activities be performed in accordance with ASME B30 series standards. The BEA Hoisting and Rigging Program conforms to LWP-6500, "Lab-Wide Procedure Hoisting and Rigging at the INL." LWP-6500 was revised (i.e., Revision 6) to align with the 2011 version of DOE-STD-1090. In addition, Revision 6 to LWP-6500 referenced PDD-9001, "Nuclear Management System Program," which provides commitment to follow the hoisting and rigging program at INL. Revision 6 of LWP-6500 also describes the management responsibilities (as related to the hoisting and rigging program at BEA), and defines the various performers and their applicable responsibilities (as related to hoisting and rigging at BEA). Revision 6 to LWP-6500 also provided alignment with CTR-650, "Hoisting and Rigging Committee," which committee was reinstituted in 2011 , to handle issues that arise at INL that pertain to hoisting and rigging activities. 
The BEA Hoisting and Rigging program continues to perform safely and efficiently at the various facilities managed by BEA. More rigorous controls are in place when critical lifts are performed as compared to ordinary lifting evolutions. However, per LWP-6500, a designated leader has responsibilities that must be performed for ordinary lift evolutions also. BEA does not have a formal material handling process, which also poses a risk.

Improvements are consistently being made to the BEA hoisting and rigging program, which are aimed at improving safety and efficiency within the area of hoisting and rigging. During 2012, the following hoisting and rigging forms were revised: Form 433.21, "INL Mobile Crane Setup Plan;" Form 433.34, "INL Lift Plan;" Form 433.36, "INL Hoisting and Rigging Critical Lift Person in Charge (CLPIC)." The hoisting and rigging training program is contained in PDD-144, "INL Hoisting and Rigging Training Program." The training program was also revised in 2012.

Assessments have been performed at INL for hoisting and rigging activities. In addition to assessments being performed, ICAMS is being utilized by BEA personnel. During 2012, there were many issues and observations provided into the ICAMS database, which were related to hoisting and rigging activities. This level of activity demonstrates that observations are being performed across the INL facilities managed by BEA.

Site facilities (ATR Complex, CFA, MFC, and SMC) are well represented as related to hoisting and rigging Conduct of Operations. However, the facilities in town and miscellaneous INL programs that continually perform work at offsite locations and then back onsite can be strengthened. These types of programs (and the personnel within them) need to be represented on the INL Hoisting and Rigging Committee. Once these programs are involved on the Hoisting and Rigging Committee, the respective line management will be able to better manage the risks associated with hoisting and rigging, and safety will be improved.

Another area that can be improved, as related to the BEA hoisting and rigging program at the various facilities, is the performance of surveillances and assessments. The BEA Hoisting and Rigging Committee is working to develop metrics and objectives to ensure BEA is meeting DOE expectations. Once this assessment program is developed (as related to hoisting and rigging operations at BEA), further enhancements and improved safety of hoisting and rigging activities will be achieved. It is important for each individual area to ensure low-level issues are placed into ICAMS so that better trending can be completed.

Finally, the BEA hoisting and rigging program needs to be more visible/accessible to BEA personnel, so that personnel can easily find help when questions arise.

As described above, the BEA hoisting and rigging program is continually being improved. The scope of the hoisting and rigging program is well defined (i.e., perform hoisting and rigging activities at the various INL facilities managed by BEA safely and in accordance with DOE-STD-1090). Hazards associated with hoisting and rigging are well understood. The execution of the BEA hoisting and rigging program as contained in LWP-6500 and RD-2007, "Hoisting and Rigging," provide the direction to safely perform hoisting and rigging activities at INL. The hoisting and rigging training program, as contained in PDD-144, provides the training so that workers can perform hoisting and rigging activities safely and in compliance with regulations and national safety standards. The BEA hoisting and rigging committee meets regularly to discuss feedback and determine areas for improvement. 


\subsubsection{Asset Protection}

Asset Protection MS. A MS applicability matrix was developed to identify the critical management system interfaces between the functions of the Asset Protection management system and other BEA management systems. The applicability matrix was used to communicate and validate system interactions with other management system leads, functional leads, and SMEs to gain improved risk management, more efficient resource use, and increased customer satisfaction.

The Safeguards and Security function was restructured into five separate functions to better manage applicable source requirements and align implementing procedures. The restructuring also improved integration with other BEA management systems and functions.

\subsubsection{Contractor Assurance}

Laboratory Performance. In FY 2012, Laboratory Performance began a comprehensive review of the CAS processes, procedures, and tools for the purpose of reducing the complexity, and improving system usability and effectiveness. As part of the process for maturing the CAS, the Laboratory Performance organization held an independent validation review (peer review) of the CAS to evaluate the effectiveness of implementation and make recommendations for improvement. The lines of inquiry of the peer review were established from BEA's Contract DE-AC07-05ID14517, Section H, and relevant sections of DOE Order 226.1B. The review focused on the implementation and effectiveness of CAS at ATR and MFC, and how CAS outcomes from these facilities are integrated at the Laboratory level to produce a comprehensive view of laboratory performance. While opportunities for improvement were noted, the review team concluded that INL CAS is "Generally Effective," which means that the key CAS processes, tools, and practices are established, functioning, and generating outcomes that are being used to identify and mitigate risks, support management action and decision making, and improve performance.

Effective assurance activities enabled the Laboratory to understand and take subsequent action to ensure work was performed safely and effectively. The results of various assurance activities averaged over 600 issues or observations entered into ICAMS each month. These activities helped identify substantive issues for which CAPs were created to enable improved performance. INL proactively identified approximately $95 \%$ of issues, versus issues resulting from an event or identified externally. The severity of operational events has declined.

The quality of event investigations has improved. The Corrective Action Review Boards (CARBs) are consistently driving toward systemic learning during corrective action reviews.

Metrics and targets to assess the effectiveness of operational performance are in place. Performance metrics have been developed and given ongoing management attention in key operational areas such as the ATR Management Review Meetings (MRMs) and MFC's Management Review Committee meetings. These metrics are driving understanding current performance, shared ownership, and the ability to make predictive modeling of future performance.

Promotion of predictive measurement is a priority effort by Laboratory Performance.

Improvement Initiatives/Actions scheduled in FY 2013 include:

- Revise and Publish CAS procedures as "pending"

- Complete updates to tools (ICAMS, Independent Assessment System [IAS], lessons learned)

- Complete training for stakeholders for CAS process and tools

- Roll out revised procedures 
- Complete development of new performance metrics

- Complete workshops with portfolio owners

- Issue performance standards for Leadership Management Team (LMT) (reinforcing the strategy and scorecard)

- Complete one-on-one meetings with LMT representatives

- Communicate performance against standards (scorecards).

Occurrence Report Summary. During FY 2012, the trends are a decreasing number of Significance Category (SC) 2 and SC 3occurrences (i.e., decreasing severity). There was a $15 \%$ reduction in the number of reports submitted in the most recent 12-month period over the previous 12 months

(76/89 reports). There were three occurrence reports in the each month in the latest quarter, which is less than half of the previous 12-month average. No SC 2 or higher occurrence report was identified in the most recent quarter, which has not happened in the previous 28 quarters. There have been no additional hazardous energy related events reported in the months of July through September, which was identified as a high number (seven reports) in the previous quarter.

\subsubsection{Contractor Assurance Improvements}

A CAS Peer Review IAS 122367 concluded "generally effective" implementation and resulted in fourteen opportunities for improvement (OFIs). All OFIs Corrective actions are under development that will be tracked to completion. Results of the peer review validated improvement actions indentified to date by Lab Performance and prompted the additional risk planning and metrics workshops conducted by each of the applicable councils. . A major theme from the review was the MS should drive managing the transition from an event-driven assurance approach to a performance-driven approach and a stronger integration of CAS.

Additional assessments with direct ties to the Contractor Assurance Management System Effectiveness include IAS122224, "Effectiveness of Consent Order NCO-2010-04," IAS12107, "Effectiveness Assessment of INL Work Control Corrective Action Plan," PLN-3762, and IAS122317, "MFC ZPPR Corrective Actions Review." Outcomes of the assurance activity were overall "effective." A positive theme was good sustainment efforts of improvement actions (such as with sustained excellence plans for ATR, MFC, and RadCon). CAS-specific results of these assurance activities are captured in ICAMS and include opportunities to improve to the Management Observation Program (clarifying INL expectations on entries in ICAMS, ensuring meaningful results), and implementing the high-volume low consequence program (trending, consistent entry of concerns into ICAMS).

Numerous effectiveness reviews targeted corrective actions to verify demonstrated change has occurred in culture, behaviors, and processes. Management reinforced expectations to find, fix, and own problems demonstrated by use of the issues management system, Issues Screening Teams, and the use of CARBs and Management Review Committees (MRC). For instance, ATR assessed the effectiveness of the corrective actions for the low level of fuel in the ATR vessel, INL Hazard Identification and Controls, and conduct of infrequently performed tests or evolutions against industry standards. Other effectiveness reviews addressed corrective actions related to events throughout the year in addition to the larger scale corrective actions such as those associated with the ZPPR plutonium contamination event. Across operations inspections and surveillances were performed on work control processes including operations, welding, LO/TO, configuration management, fire safety, maintenance, training, radiation protection, security, and emergency preparedness and those processes tied to corrective action plans. Issues of substance are routinely identified related to systemic issues and behaviors. 


\subsubsection{Engineering}

The Engineering Management System (EngMS) implemented a new conduct of engineering program at the beginning of FY 2012. This program provides guidance and a roadmap to engineering processes/procedures. The conduct of engineering program emphasizes engineering's role with the core functions of ISMS and provides procedures that guide engineers through an engineering lifecycle that produces safe and effective engineering deliverables.

The EngMS has worked to integrate engineering requirements between the Research Management System, the Project Management System, and Maintenance. This integration effort has resulted in changes to EngMS processes/procedures as well as changes in the other management systems.

Criticality safety processes/procedures have been improved to analyze the hazards and develop controls for prevention and mitigation of a criticality accident. Criticality Safety Evaluations (CSEs) are performed that identify and document the controls.

Facility Safety processes/procedures have been improved to address the requirements and guidance for safety analysis, the planning of safety analysis tasks, and the preparation of facility categorization and safety basis documents.

Improvement initiative actions for FY 2013 are:

- The EngMS continues to work on improvements to the System Engineering program, the configuration management program, and the INL Engineering Standards. Legacy issues related to configuration management continue to be the primary risk area that the EngMS is working to improve.

- The configuration management program is a part of the overall System Engineering program and both of these programs have improvement initiatives that are underway.

- The Configuration Management program provides processes for controlling the design, documentation, and physical configuration of structures, systems, and components, including software that are important to the protection of workers, the public, and the environment and are important to the accomplishment of critical missions and operations.

\subsubsection{Environmental}

Environmental Management System (EMS) successfully achieved ISO 14001 Re-registration for a 3-year period beginning in November 2011. ISO 14001 Registration is evidence of recognition that INL's EMS utilizes processes and systems that are fully analogous to the core functions of ISMS.

The INL Sustainability program was awarded the U.S. Department of Energy Sustainability Management Award in November 2011. The team was recognized for integrating sustainability into INL policies, standards, processes, and operations. The expansion and integration of the waste diversion program was recognized as part of this award. This award recognizes the EMS's incorporation of controls that implement sustainability measures into INL work processes and performance and result in continuous improvement in the area of sustainability.

BEA was awarded the 2012 Federal Electronics Challenge (FEC) Silver Level Award for FY 2011 Activities at a ceremony held in Washington, D.C. This award satisfies a FY 2012 commitment, and some of the FEC activities satisfied both INL's Site Sustainability Plan goals and BEA's FY 2012 Performance Evaluation Measurement Plan (PEMP) milestones. 
Improvement initiative actions include:

- An environmental regulatory strategy documenting a systematic approach to interactions with regulators based on the nature of the issue, as well as a more systematic approach to reducing and simplifying requirements has been completed. The strategy identifies hazards and controls that help to assure INL compliance with regulatory requirements. The regulatory strategy also addresses the regulatory requirements and schedules for supporting INL's 2013-2022 Ten-Year Site Plan and its successor plans. The strategy is available in the Electronic Document Management System (EDMS) as PLN-8200, "Environmental Regulatory Strategy." The strategy will be updated to address the update to the Ten-Year Site Plan.

- BEA continues to refine and develop process improvements in preparation of the annual Emergency Planning and Community Right-to-Know Act (EPCRA) 313 reporting. Changes in the process this year included standardization of data report format used at all facilities at INL, which then allowed these to be linked together by chemical so the total quantity used by chemical could easily be calculated. The use of these standardized forms resulted in almost complete elimination of any comments from DOE on the chemical usage report. These process improvement changes resulted in a savings of greater than $\$ 35,000$ in completion of the EPCRA 313 report this year. It is anticipated that these savings will also be realized in completion of the EPCRA 313 reports in the future. Ongoing process improvements reflect a commitment to continuous improvement and employee involvement in identifying potential improvements.

- Based on internal assessments, field observations, and regulatory inspections, no environmental instructions have been found to fail to accurately implement regulatory requirements, although the trending of environmental ICAMS issues continues to indicate that procedure implementation is a cause of some environmental-related ICAMS issues. Deeper investigation is underway to determine whether instructions can be improved to reduce or eliminate these issues.

\subsubsection{Enterprise}

With the need to streamline processes and simplify work, the System Architect software tool was retired, which was used to document MSs data and graphically-delivered procedures. The data consisting of the list of MSs, their associated functions, descriptions, and points of contact were moved and integrated with the Dynamic Object-Oriented Requirements System (DOORS) software- the application used to manage contractual and regulatory requirements roll-down information. The completion of this effort collocated all MS description data and requirements eliminated the need to process Electronic Change Requests (eCRs) to modify MS data, removed the need to manage 109 System Architect Object (SAO) diagrams, and increased the reliability and availability of access to MS data that was made unavailable due to breakdowns in complicated connections between the two software tools.

With the retirement of the System Architect tool, a new guide was drafted to manage the overall construct of MSs at INL. This included new R2A2s for MS players, web accessibility, and plans for restructuring the Enterprise MS to incorporate Communications, administrative standards, and laboratory strategic planning. A lapse in reporting of this MS was addressed with the Management Council in July, with approved plans to reinstitute an assurance portfolio to monitor the effectiveness of the processes used for managing INL MSs, and a strategic plan to address maturing INL MSs to a highly effective level.

During FY 2012, several gaps in MS administration, procedure dispositions associated with legacy MS actions, and gaps in MS Lead assignees and competencies were recognized, addressed, and resolved. 


\subsubsection{Financial}

The focus of the Financial MS (FMS) with regard to safety is on implementing direct and indirect budget development processes that require the consideration of environmental, health, and safety risks within a balanced priority framework. In the face of increasing downward pressure on indirect budgets the FMS added additional risk assessment rigor to the FY 2013 indirect budget development process. These requirements were outlined in the FY 2013 Indirect Budget Call issued by the INL Chief Financial Officer on May 30, 2012.

Together with the Contractor Assurance MS, FMS utilized a lab-wide risk register coupled with previous lessons learned to proactively highlight budget reduction areas of concern, and balance budget decisions accordingly.

\subsubsection{Human Capital}

One of the most important functions of the Human Capital MS where incorporation of ISM principles by design into associated processes is vital is the Training function. Several accomplishments in this area were achieved in FY 2012. Accomplishment improvements include, but are not limited to:

- Completed major revisions to the LO/TO qualification program to address identified gaps.

- Completed major revisions to the Radiation Worker qualification program to include valid and reliable practical exams, YouTube-type videos on specific skills, Human Performance Improvement (HPI) concepts, and increased skills training in the initial training.

- Initiated a customer relationship management model for focused customer support for the INL Science and Technology (S\&T) (National and Homeland Security [N\&HS], Energy and Environment [E\&E] S\&T, and Nuclear S\&T) and Quality Assurance organizations.

- Designed, developed, and implemented the new "Laboratory Radiation Worker Qualification" program in support of S\&T research efforts.

- Reduced the number of trainees requiring Radiation Worker qualifications to cut costs and improve quality.

- Assembled and installed a new operating Closed Loop Simulator in CFA-1606 to provide dynamic learning opportunities for operations, maintenance, and other support personnel in support of Conduct of Operations and Maintenance.

- Designed, developed, and implemented a dynamic learning lab at the Willow Creek Building (WCB) to train new hires and high risk supervisors, foreman, and above on ES\&H, Security, and Work Control fundamentals and expectations.

- Provided substantial support to both MFC and ATR in the performance of DOE-STD-1070-94 training assessments. These assessments are the vehicle for nuclear facilities to demonstrate compliance with DOE O 426.2, Training and Qualification of Personnel.

- Consolidated the Training Coordinator (TC) function across the lab to improve quality and to reduce costs.

- Moved 215 lab-wide course case files from a manual record system to EDMS-controlled documents to improve services ensure record retrieval reliability and gain efficiencies. 
- Supported the successful certification effort for ISO 14001 through presentations to the external assessment team and by providing training completion reports as needed.

- Completed the conversion of Training Records and Information Network (TRAIN) user interface from Oracle Forms to ASP.NET. Ultimately this allows for improved usability and integration with other lab systems.

Ongoing Initiatives. Five major improvement initiatives for the training program for FY 2013 include:

- Implementing an efficient training delivery schedule where instructors average $<75 \%$ of their time with a classroom fill rate of at least $80 \%$

- Helping our instructors, both EITC and others, transition to "course owners"

- Finishing the update of Manual 12 with associated job aids

- Finishing revisions and implementing the instructional elements of the following lab-wide training programs: Work Planner, Nuclear Conduct of Operations, LO/TO, Hoisting and Rigging, and Instructor

- Implementing the approved HPI Program Description Document and Plan, including implementation of a Dynamic Learning course for the INL high-risk leaders.

Successful completion of these initiatives will add significant value to the laboratory, raise the bar on training expectations, and help ensure safe and reliable operations across the INL enterprise.

Improvements to the training assurance portfolio and metrics were identified for FY 2013 to better indicate training program strengths and weaknesses. Many of the current indicators are more focused on how much training activity has been accomplished rather than how well training needs are being met. Metrics and commitments are being established to ensure performance and improvement in the following areas:

- Training standards, policy, and procedures

- Employee individual training plans

- Lab-wide training curriculum

- Instructor technical and instructional qualifications

- Training records

- Employee competency.

\subsubsection{Occupational Safety and Health}

Occupational injury and illness performance through FY 2012 continues to reflect improvement and is one of many indicators of safety culture. FY 2012 has been the safest ever for BEA employees since the inception of INL. There were a total of 29 Recordable occupational injury and illness cases involving BEA employees occurring during FY 2012, resulting in a TRCR of 0.78 . This represents an improvement of $34 \%$ compared to the FY 2004 baseline, and is over $20 \%$ better than FY 2011 . Of the 19 major organizations comprising the laboratory, 10 completed FY 2012 without incurring an OSHA recordable injury or illness. Six of these 10 organizations also had no OSHA recordable cases during all of FY 2011. Twelve of the 19 major organizations did at least as well or better, from a TRCR perspective, in FY 2012, as compared to FY 2011. 
The resulting DART Case Rate for FY 2012 is 0.32 . This represents an improvement of over $47 \%$ compared to the FY 2004 baseline, and is almost $40 \%$ better than FY 2011. Of the 19 major organizations comprising the laboratory, 14 completed FY 2012 without incurring a DART case, and 16 organizations did at least as well, or better, from a DART Case Rate perspective, in FY 2012, as compared to FY 2011.

FY 2012 has also been the safest ever for BEA select subcontract employees since the inception of the INL. During FY 2012 there were no occupational injuries reported involving employees of select subcontractors that were classified as recordable. The resulting collective Select Subcontractor TRCR for FY 2012 is 0.00 , down from the 2.35 for FY 2011. This metric is not amenable to an annual goal, due to the variation in volume of subcontractor work scope and resulting work hours. Rather, the metric is used to monitor individual subcontractor occupational injury and illness performance while performing work onsite, and to take action, as appropriate, if performance does not meet expectations.

The metric associated with Injury and Illness rates is only one of several that INL monitors to help ensure that safe processes are developed and implemented to ensure the safety of INL personnel. The overall objective at the end of the day is that INL personnel return home each day in the same safe condition that they arrived to perform work. Additional metric and analysis information is àvailable on the CAS portal.

\subsection{Leadership Engagement Culture Improvements}

This ISMS review also included looking at the results of the FY 2012 Safety Leadership survey. The Integrated Safety Management Energy Facility Contractors Group (EFCOG) was the impetus for INL to further safety excellence by measuring and assessing their safety culture proactively. A strong persuasive safety culture is important because it has an influence on actions and decisions implemented to improve ISM. A Safety Leadership initiative and survey was launched in FY 2010 and has continued to further sustain safety excellence. INL's goal was to improve the ability to assess, select, develop, promote, and reposition INL management, and continually improve organizational performance. The survey continues to monitor the norms and provide frequent feedback to management and employees.

Safety leadership at INL promotes respecting and caring about employees. Safety leadership was designed to strengthen trust, leadership, personal responsibility, communication and integration, performance, ensure effective processes, enhance organizational learning, increase organizational alignment, and create dialogue between management and employees.

In 2012, the third assessment of the safety culture survey was provided to BEA employees. The survey provided insights and data to understand the overall health of Safety Culture. Overall, results reflected a strong positive correlation for safety as an internalized value at INL. The data was gathered, analyzed, and charted. Individual organizations were briefed and given positive and negative results. Ten organizations that were targeted for intervention, due to their scores being below the mean were coached and mentored. These organizations developed strategies to improve performance for transforming their safety culture and presented those strategies to the Operations Council.

Organizational learning and recognition and rewarding safe behavior continue to be areas needing more intervention institutionally. Mandate to Manage training has incorporated a section emphasizing continued improvements in this endeavor.

In 2013, the survey is transforming from safety leadership to a more comprehensive review of organizational effectiveness, culture, leadership, and employee engagement. This merger will allow further understanding of cultural attributes that will enhance operational and research performance, growth and business sustainability, as well as safety performance. 


\subsubsection{Voluntary Protection Program (VPP)}

Voluntary Protection Program (VPP) achieved numerous successes over the past year on the path toward the Star recertification anticipated to be conducted in 2013. A few noteworthy accomplishments are mentioned below.

New Chair/Vice-chair Training Module. A revamped training manual was developed and distributed to employee safety team (EST) chairs and vice-chairs at the Team Building collaboration meeting held in February. The manual includes such things as roles and responsibilities, contacts, the filing matrix system, subcommittee expectations, funding guidance, and aids for conducting inspections. The manual is also accessible electronically on the VPP Nucleus Community.

Focused Define, Observe, Intervene, and Test (DO-IT)s. Laboratory concerns dealing with deficient use of handrails and improper parking lot behaviors were elevated to the laboratory employee safety team (LEST). Two processes for DO-ITs were conducted by ESTs at isolated facilities to promote safer behaviors with regard to these concerns. Interventions included different modes of communication to encourage safer behaviors of pedestrians and drivers (Intervention Cards, Strategically located Posters, Team talk, EST discussions, etc.). Testing will continue and additional interventions will follow if necessary.

Timeout/Stopwork Procedure. INL's LWP-14002, "Timeout and Stop Work Authority," was revised. The August workplace safety brief "Make the Right Choice - STOP WORK" summarized these changes and reminded employees that they have the responsibility, authority, and right to take a timeout and/or stop work, without reprisal, when it is believed that an unsafe condition or condition adverse to quality, or an at-risk human behavior exists.

VPP Safe Driving Campaign. BEA-VPP focused on six driving behaviors with thought provoking posters to capture employee attention. Topics included "Could you Stop in Time?" (the need to adjust speed accordingly), "drive SMART" (five behaviors for driving safely), "Look Right, Look Left" (watch for cyclists), "Park the Phone" (concentrate on just driving), "Heed the Sign" (know the school zone speed), and "Know the 511 " (the number for 24/7 road information to make better decisions for driving in winter). INL shared this information with other Laboratory contractors.

\subsubsection{Integrated Safety Management System (ISMS)}

During FY 2012 the ISMS program office rolled out new ISMS Refresher Training Classes, 0INL1526M for Managers and 0INL1526 for all employees with $>95 \%$ completion rates in both classes. In addition, a supplemental ISMS Success Tree awareness video was developed for refresher and new hire training.

Improvements to the ISMS program:

- Improved Management System Lead and ISM Requirements Interface, communicated more thorough understanding and expectations.

- Updated improvements to the CAS portal for providing clearer paths and understanding access to DOE. 
- New Management System Home Page on Nucleus and further defined R2A2s for MSLs are pending.

- Progressed from Specific Limited SPOMC to more comprehensvie Quarterly Assurance Report safety related metrics, consolidated CDRL H.09 and H.18

- Revised and improved PDD-1004 to include useful tools for management system leads to use and understand how their management system implements ISMS core functions and guiding principles for the Laboratory.

In an attempt to keep this report as concise as possible, the remaining MSs that have not previously been discussed, although significantly important to the INL ISM implementation, will not be included in this report. However, more information is available on each MS through access to the CAS portal on the INL Nucleus home page. 


\section{IDENTIFY STRENGTHS OF ISMS IMPLEMENTATION}

INL routinely completes high-risk and high-hazard projects, which include research, nuclear operations, construction, routine work evolutions, and maintenance activities. The vast majority of these activities are completed without incidence due to extensive implementation and integration of the five core functions and eight guiding principles of ISM. These ISM core functions and principles are embedded in numerous planning, prevention, procedures, tools, and processes.

The assessment team decided to include (below) just a few of these success stories that depict extensive planning and hazard mitigation and implementation of the five core functions and eight guiding principles of ISM.

\subsection{MFC Stack Cable Upgrade}

Depicted in Figure 4 below, INL replaced nine existing guy wires on the 200 - $\mathrm{ft}$, glass-lined MFC stack. This was a $\$ 685 \mathrm{~K}, 4$-month project with over 7 weeks of construction activities completed with significant events. Demonstrating effective implementation of ISM core functions and guiding principles. Some of the hazards that were mitigated included: elevated work, heavy equipment, excavation, contamination, weather restrictions, stack discharges, cable tension, concrete work, and falling objects.
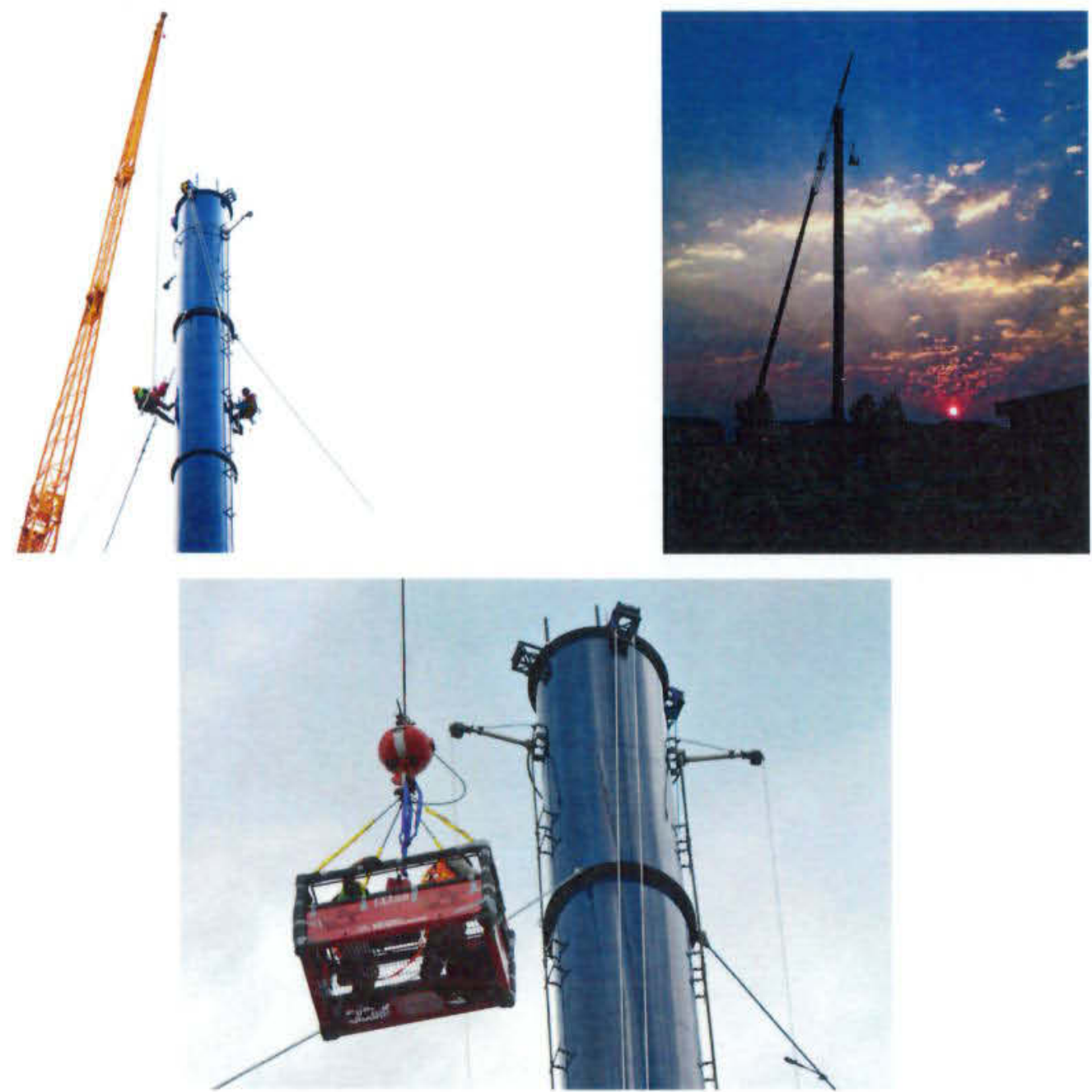

Figure 4. MFC stack cable upgrade. 


\subsection{Cold Crucible Induction Melter (CCIM)}

The Cold Crucible Induction Melter (CCIM) shown below in Figure 5 is a test system designed to develop better methods of treating high-level waste and configuring them to a glass ceramic waste form.

Hazards that were mitigated included: high-voltage induction coil, high radio frequencies, complex LO/TO, high temperatures (1300 Celseus), molten glass, heavy lifting and cramped spaces, compressed gases, heavy metals, hazardous chemicals, etc.

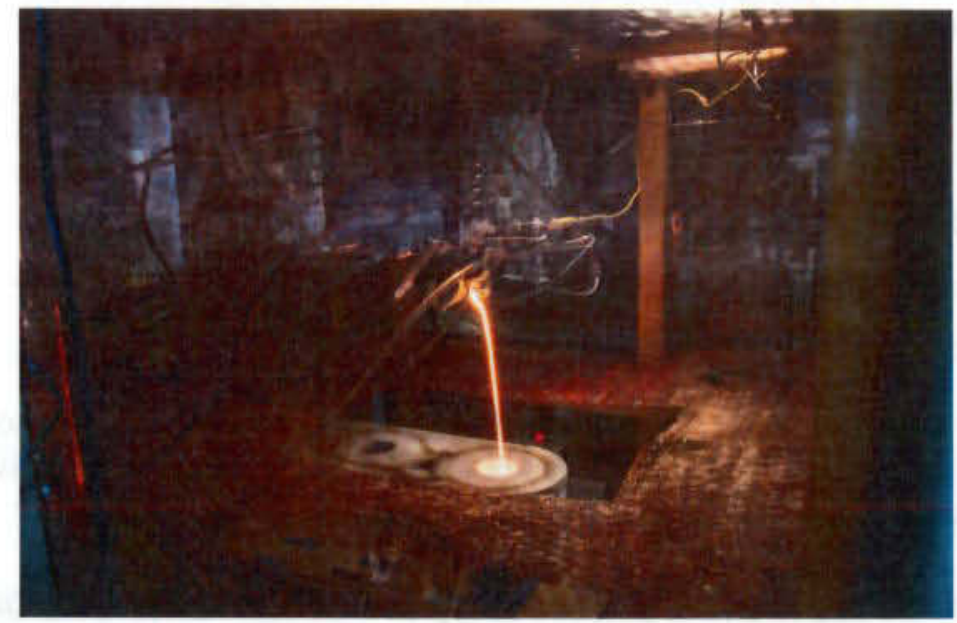

Figure 5. Cold Crucible Induction Melter.

\subsection{Demonstration of Technologies used to Decontaminate Porous Surfaces used for Infrastructure such as Concrete, Granite, and Marble}

As depicted below (see Figure 6), INL has a contract with Battelle Memorial Institute/Environmental Protection Agency (EPA) to test various decontamination technologies to be used to clean up after an urban radiological dispersion device has been detonated. Test coupons are contaminated with radioactive nuclide materials to specified levels. Samples are then placed inside a large tent at Idaho Nuclear Technology and Engineering Center (INTEC) 653 for testing of the decontamination technologies.

Hazards that were mitigated included: radioactive material, cesium, strontium, americium, elevated work, heat stress, power tools, and chemicals.

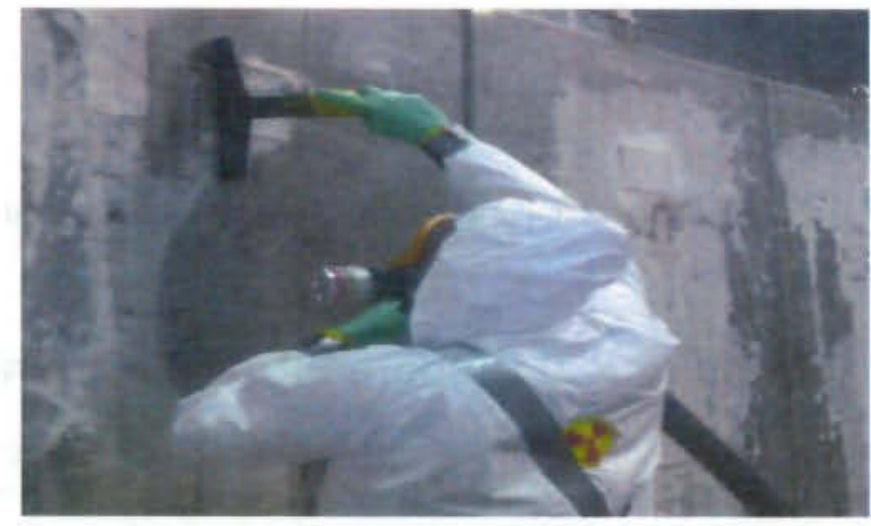

Figure 6. Decontamination of porous surfaces. 


\subsection{Hot Fuel Examination Facility (HFEF) Decon Cell Entry and Air Pallet Upgrade}

This work activity had several work planning improvements that were implemented prior to the work being performed due to questioning attitudes by BEA workers. While this indicates a weakness in work planning it also demonstrates the questioning attitude and willingness by workers involved to get it right. The overall scrutiny was elevated and it is a good example of heightened awareness and sound ISMS effectiveness. This work activity required manual entry into the decon cell of HFEF to perform significant upgrades and repairs included:

- Replaced air bearings on decon cell shield plug

- Repaired sump pump for spray chamber

- Repaired turntable for the spray chamber

- Changed out actuators, latches, and rams on spray chamber doors

- Replaced a section of rabbit system piping.

Hazards that were mitigated included: contamination, radiation, heat stress, atmospheric hazards, all work was done while on breathing air, general hand tool hazards, elevated work activities, heavy lifting, $\mathrm{LO} / \mathrm{TO}$, and all work was done while on breathing air.

\subsection{Homeland Security E3 EMP Simulation}

In September 2012 completed the Magneto Hydro Dynamic (MHD-E3) Power Production Experiment (E3 is a portion of the electro-magnetic pulse caused by either a high-altitude nuclear detonation or a geomagnetic storm) test designed to simulate the electromagnetic pulse effects, which can be caused by a geomagnetic disturbance and identify the damaging effects caused by this disturbance on power system components such as large power transformers.

The following hazards were mitigated during the execution of this work:

- Elevated work on the INL $138 \mathrm{kV}$ transmission work performed by Power Management

- Lock-out/Tag-out

- Working from bucket trucks and man lifts

- Hoisting and rigging

- Extended shifts from 6 am to $8 \mathrm{pm}$ on several days

- Multiple subcontractors working on the same jobsite

- Numerous visitors during test operations

- 725 VDC battery operations

- Grid connected testing of new electrical apparatus (EMPrimus neutral ground blocking device)

- Plus many other hazards.

\subsection{Radiological Dispersal Device Training}

INL developed and conducted monthly Radiological Dispersal Device radiography training courses for Department of Defense customers at the Transient Reactor Experiment and Test Facility (TREAT). Hazards included high radiation exposure devises and radiography operations. 


\subsection{GE-2000 Hot Spot Recovery}

ATR Radiological Control staff played a vital role in oversight of the safe and successful outcome of the GE-2000 Hot Spot recovery. This included initial response actions, extent of condition surveys, postings, robotic remote surveys, recovery efforts, mockup training and ultimately the final disposition of the 4,000 R/hr hot spot. The ATR Complex recovery team successfully isolated and removed the $4000 \mathrm{REM} / \mathrm{hr}$ hot spot source from the ATR canal area. This activity was performed flawlessly and completed under the ALARA dose.

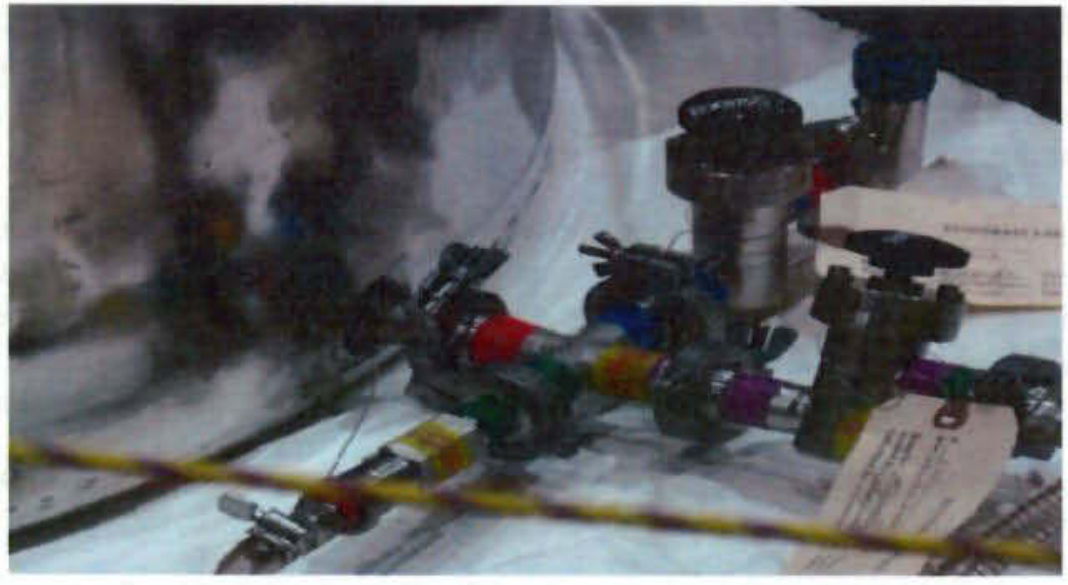

Figure 7. GE-2000 cask vent cross hot spot.

\subsection{Zero Power Physics Reactor (ZPPR) Decontamination and Recovery Effort of Fuel Plates}

Numerous MFC Radiological Control staff oversaw the successful effort with R\&D, Operations, and Safeguards and Security to successfully recover fuel plates and decontaminate the ZPPR fume-hood. 


\section{AREAS IDENTIFIED FOR IMPROVEMENT}

Improvement is essential to maintain a successful ISM program. Continual organizational learning that takes place provides an avenue for predictive and preventative endeavors. MSLs have demonstrated an elevated effort of monitoring their MS and making improvements as necessary.

BEA recognizes there is an opportunity for improvement in the timely implementation of corrective action plans and the completion of adequate closure documentation. Throughout the year BEA management has rejected the completion of some corrective actions based on actions not being performed as written or the closure documentation was not written so that a third party would be able to understand how the corrective action was completed without having the day-to-day working knowledge of the facility. BEA has acquired some additional external training that will begin early in December FY 2013 that will assist in addressing this concern.

Promotion of predictive measurement is a priority effort by Laboratory Performance. Laboratory Performance will be meeting directly with each Directorate or Management System Assurance Portfolio Owner to ensure understanding and expectations of a newly updated template for planning Assurance (TEM-13730) as a follow-up to risk and metric-related workshops held in early FY 2013. Additionally, Lab Performance will measure the quality of assurance portfolio reports quarterly beginning FY 2013 Q1.

In FY 2012, Laboratory Performance began a comprehensive review of the CAS processes, procedures, and tools for the purpose of reducing the complexity and improving system usability.

As part of the continual improvement process, the following opportunities for improvement were noted. Some are already being addressed through corrective actions, training, or organizational efforts. Others are being planned for in FY 2013.

- Corrective Action Plans (see detail in Section 3)

- Ensure problem statements and corrective actions are clear, specific, measureable, and address the causal factors

- Provide closure documentation that fully addresses the CAP items, it written clearly, is thorough, and understandable to third-party reviewers

- Ensure timely implementation of corrective action plans and the completion of adequate closure documentation.

- Laboratory Performance (see detail in Section 3)

- Review of the usability of CAS processes (e.g., portfolio development, risk mitigation) and tools (e.g., ICAMS, IAS) and assess opportunities to reduce complexity and increase usability and integration

- Promote and instruct portfolio owners in the use of predictive measurements.

- Management Systems (see detail in Section 3)

- Increase integration and engagement of management systems with ISMS principles and processes (e.g., identify ISM interfaces, monitor ISM execution, metrics to trend, and evaluate ISMS effectiveness)

- Improve the timeliness of management system quarterly reporting to facilitate analysis and ensure committeemen's to DOE-ID for exhibiting Safety Performance objectives and commitments are met. 
- Hoisting and Rigging (see detail in Section 3)

- Expand the representation of the BEA/INL Hoisting and Rigging Committee to include Research Education Campus (REC) and other projects that perform hoisting rigging

- Increase the use of focused surveillances and assessments for hoisting and rigging

- Promote lessons learned and use of ICAMS, and improve accessibility to SMEs so that personnel can easily find help when questions arise. 


\section{ISMS SAFETY PERFORMANCE OBJECTIVES, PERFORMANCE MEASURES AND COMMITMENTS}

INL reports on the SPOMC quarterly through the management system quarterly assurance reports that are posted to the CAS portal for DOE-ID's review. Each MSL has the responsibility of evaluating performance and improvement to their management system with respect to safety related metrics, and to work closely with their DOE counterpart and keep them informed when changes to the metrics within the reports are made. This transparency is intended to improve the understanding of safety related metrics and the communications between MSLs and DOE-ID.

The majority of the INL's MSs play a role and facilitate the integration of safety core functions and guiding principles throughout INL's operations and processes that manage the Laboratory. However the key management systems that play a significant role and have established safety related metrics for continuous improvement are:

- Asset Protection

- Contractor Assurance

- Quality Assurance

- Occupational Safety and Health

- Radiation Control

- Environmental

- Work Management.

As previously mentioned in Section 4.2 there have been many notable improvements to MSs during FY 2012. MSLs have been tasked in FY 2013 to scrutinize the content of their safety related metrics to ensure that they are measuring key elements and functions applicable to INL's successful implementation of safety related improvements.

INL MSs are based on the principle of continually improving in key areas that impact the sustainability of the business, encompass sharing, promote process optimization and management focus and disciplined management thinking.

In addition to improvements in the quality of metrics and critical evaluation of performance as documented in the content of quarterly assurance reports, each of the MSLs were challenged to better understand the application and implementation of ISM in their MS by being more self-critical to improve their efforts to protect people, environment, and assets. Also they were challenged to develop measurement tools to examine and identify ISM deficiencies and incidents to prevent them from recurring.

In FY 2012 each MSL provided summary evaluations of their respective management system's health and performance for FY 2012 to the ISMS program manager. These evaluations included accomplishments, opportunities for additional improvements, and ongoing initiatives. The review of these evaluations demonstrated sustained commitment to SPOMC and effective ISM implementation at INL.

For further detail and analysis of the MSs, visit the CAS portal quarterly assurance reports. 


\section{ANNUAL EFFECTIVENESS REVIEW AND DECLARATION RESULTS}

\section{A. Issues}

No additional issues that are not already being addressed.

\section{B. Opportunities for Improvement}

1. Sustained improvement efforts in Work Control and Radiological Work Performance (PLN-4030 and PLN-4145, respectively) need to continue as planned and re-align as necessary to achieve the desired results. ISMS will follow progress on these improvements.

2. A self-critical analysis needs to be completed on each of the Management Systems Assurance Report content, identifying the validity and purpose that the information serves to benefit the overall health determination of the MS and its role with respect to ISM. Quality versus quantity needs to be the emphasis for this to be successful. The second part to this evaluation should determine the necessary resources and ensure that they are appropriately allocated.

3. Timeliness of posting quarterly assurance reports to the CAS portal needs to be improved to ensure commitments and customer satisfaction to DOE-ID for exhibiting Safety Performance Objectives and Commitments are achieved. BEA needs to ensure expectations are clearly defined and incorporate a system that achieves accountability.

4. REC and miscellaneous INL programs that do not fall under the guidance and representation of CFA, MFC, SMC, and ATR complexes need to be represented on the INL Hoisting and Rigging Committee. Once these programs are involved on the Hoisting and Rigging Committee, the respective line management will be able to better manage the risks associated with hoisting and rigging, and safety will be improved.

5. Promotion of predictive measurement is a priority effort by Laboratory Performance. Trending performance needs improvement, the assurance analyst personnel that track and analyze collected data for the various organizations need training on effective techniques of trending.

\section{Recommendations}

1. BEA management recognizes that there is an opportunity for improvement in the timely implementation of corrective action plans and the completion of adequate closure documentation. A CAP is in progress to remedy these issues. This is a key element to the fifth core function of ISMS, feedback, and improvement. Complete an effectiveness review after the identified improvements have been implemented.

2. BEA should develop a method to track timely posting of the MS quarterly assurance reports to the CAS portal, incorporating a system that achieves accountability.

3. MSLs should perform a self-assessment on the content of their MS quarterly assurance report to ensure ISM elements and safety related metrics are incorporated and beneficial to the analysis of the health of their MS. 
4. Management Champion of the INL Hoisting and Rigging Committee should (a) solicit representation from REC organizations to establish effective communication and roll down requirements, and (b) increase the use of focused surveillances and assessments for hoisting and rigging.

5. Laboratory Performance should develop and implement a standardized training for trending techniques.

6. ISM program manager should Benchmark other Battelle operated Laboratories' ISMS program and metrics and implement efficiency and effectiveness improvements as necessary.

7. BEA management has recognized an increased number of $\mathrm{LO} / \mathrm{TO}$ incidences. Continue with the course of action involving LO/TO and implement the necessary actions to prevent future incidence.

\section{Noteworthy Practices}

The level of engagement, attention, and resources dedicated by INL to the continual and sustained improvement of processes and issue management (transitioning from reactive to proactive) demonstrates continual improvement in the ISMS program.

\section{E. Conclusion}

INL and DOE assessments performed in FY 2012 have confirmed that the actions taken have driven immediate improvement in some cases, and appear to have long-range goals of continual improvement. BEA strongly supports ISMS functions and principles and is committed to continual improvement. The BEA Board and Operations Committee fully support ISMS as evidenced by the corporate resources they provided over FY 2012 to ensure effectiveness of ISMS. All work at INL is managed by processes and procedures that implement the ISMS five core functions and eight guiding principles. INL leaders and workers demonstrate a strong, genuine, continual, and personal commitment to ISMS elements at the laboratory, facility, and activity level. Continual improvement and maturation of the contractor assurance system and continued commitment from the INL leadership have led INL to successfully achieving a breakthrough in reducing safety incidents and improving work planning and control.

\section{Overall Performance Rating - "Effective, Continually Improving"}




\section{REFERENCES}

48 Code of Federal Regulations (CFR) 970.5223-1, "Integration of Environment, Safety and Health into Work Planning and Execution"

BEA's Contract DE-AC07-05ID14517, Section H

DOE Order 422.1, Conduct of Operations

DOE Order 426.2, Training and Qualification of Personnel

DOE P 450.4A, Integrated Safety Management System Policy

DOE-STD-1090-2011, "DOE Standard Hoisting and Rigging"

Form 433.21, "INL Mobile Crane Setup Plan"

Form 433.34, "INL Lift Plan"

Form 433.36, "INL Hoisting and Rigging Critical Lift Person in Charge (CLPIC)"

HBK 100, "ATR Fundamentals Handbook"

IAS122224, "Effectiveness assessment of the Health Physics Instrument Laboratory (HPIL) Consent Order (NCO-2010-04)"

IAS122317, "MFC ZPPR Corrective Actions Review"

IAS12107, "Effectiveness Assessment of INL Work Control Corrective Action Plan, PLN-3762"

LWP-6500, "Lab-Wide Procedure Hoisting and Rigging at the INL"

PDD-144, "INL Hoisting and Rigging Training Program"

PDD-1004, "Integrated Safety Management System"

PDD-9001, "Nuclear Management System Program"

PDD-15001, "Air Monitoring Technical Basis Document (TBD)"

PLN-3762, "INL Work Control Corrective Action Plan"

PLN-4030, "INL Sustained Operational Improvement Plan"

PLN-4058, "MFC Strategic Excellence Plan"

PLN-4058, "MFC Strategic Excellence Plan"

PLN-4145, "Radiological Control Road to Excellence Plan"

PLN-4141, "ATR Sustained Excellence Plan is Work Management"

PLN-4194, "MFC Response Plan"

RD-2007, "Hoisting and Rigging," 
